\title{
Continuous Flow Chiral Amine Racemization Applied to Continuously Recirculating Dynamic Diastereomeric Crystallizations
}

\author{
Maria H. T. Kwan, Jessica Breen, Martin Bowden, Louis Conway, Ben Crossley, Martin F. Jones, \\ Rachel Munday, Nisha P. B. Pokar, Thomas Screen, and A. John Blacker*
}

Cite This: J. Org. Chem. 2021, 86, 2458-2473

Read Online

ACCESS | Lill Metrics \& More | 国 Article Recommendations ｜ st Supporting Information

ABSTRACT: A new, dynamic diastereomeric crystallization method has been developed, in which the mother liquors are continuously separated, racemized over a fixed-bed catalyst, and recirculated to the crystallizer in a resolution-racemization-recycle $\left(\mathrm{R}^{3}\right)$ process. Separating the racemization from crystallization overcomes problems of using catalysts in situ, that suffer conflicting sets of conditions, inhibition, and separation. Continuous racemization has been achieved through the covalent attachment of

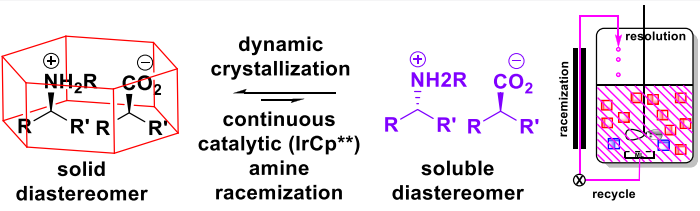
$\left[\operatorname{IrCp} * \mathrm{I}_{2}\right]_{2}$ SCRAM catalyst to Wang resin solid support to give a fixed-bed catalyst. One tertiary and a variety of secondary optically enriched amines have been racemized efficiently, with residence times compatible with the crystallization (2.25-30 min). The catalyst demonstrates lower turnover (TOF) than the homogeneous analogue but with reuse shows a long lifetime (e.g., 40 recycles, $190 \mathrm{~h}$ ) giving acceptable turnover number (TON) (up to 4907). The slow release of methylamine during racemization of $\mathrm{N}$-methyl amines was found to inactivate the catalyst, which could be partially reactivated using hydroiodic acid. Dynamic crystallization is achieved in the $\mathrm{R}^{3}$ process through the continual removal of the more soluble diastereomer and supply of the less soluble one. The solubility of the diastereomers was determined, and the difference correlates to the rate of resolution but is also affected by the rates of racemization, crystal growth, and dissolution. A variety of cyclic and acyclic amine salts were resolved using mandelic acid (MA) and ditoluoyl tartaric acid (DTTA) with higher resolvability $(S=$ yield $\times$ d.e. $)$ than the simple diastereomeric crystallization alone. Comparing resolvabilities, resolutions were 1.6-44 times more effective with the $\mathrm{R}^{3}$ process than batch, though one case was worse. Further investigation of this revealed an unusual thermodynamic switching behavior: rac- $N$-methylphenethylamine was initially resolved as an $(S, S)$-bis-alkylammonium tartrate crystal but over time became the equivalent $(R, S)$ salt. Thermal, mixing, concentration, stoichiometry, and seeding conditions were all found to affect the onset of the switching behavior which is only associated with difunctional resolving reagents.

\section{INTRODUCTION}

When racemization is used in combination with chiral resolution, it is a powerful alternative to the asymmetric synthesis of chiral amines. These intermediates are used widely in the pharmaceutical and fine chemical industries but are often difficult to make in large quantities and as a result can be costly. ${ }^{1-4}$ While catalytic asymmetric synthesis has largely superseded inefficient stoichiometric methods, both chemoand biocatalysts often perform poorly with highly functionalized compounds with issues of regio- and enantioselectivity, competing ligands, solubility, and product separation. ${ }^{5}$ Racemic starting materials are commonly resolved using enantioselective enzymes ${ }^{6}$ or by forming and breaking diastereomeric salts. ${ }^{7}$ These processes are used frequently in industry, as they are simple and reliable, but they suffer low yields and high wastes. Improvements employ in situ racemization of the unwanted isomer, with the techniques known as dynamic kinetic resolution (DKR), crystallizationinduced asymmetric transformation (CIAT), and crystallization-induced diastereomeric transformation (CIDT), Figure $1 .^{8-16}$

DKR employs enzymes to react selectively with one enantiomer while racemizing the other in situ, Figure 1. The technique requires an enantioselective enzyme and substrate that racemizes under the same reaction conditions. The requirement for solvents, reactants, temperatures, and concentrations that are compatible with both catalysts compromises the optimal activity of each and reduces the overall DKR performance. CIAT works for compounds that form conglomerate crystals. The entropic barrier of going from a racemate to a single enantiomer can be overcome by adding seeds and mechanically grinding to make smaller particles, causing secondary nucleation, supersaturation, and regrowth. ${ }^{17,18}$ Despite its elegance, the method is limited in scope because too few chiral compounds crystallize with the

Received: November 3, 2020

Published: January 22, 2021

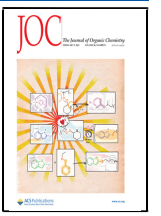




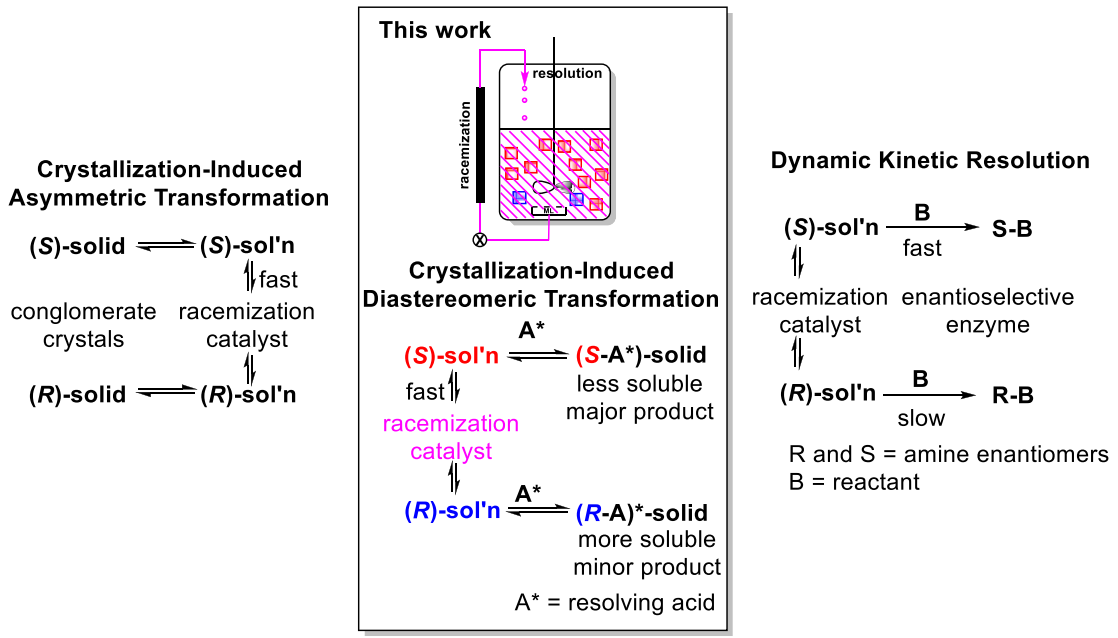

Figure 1. Dynamic techniques used in chiral amine resolution, each involving a racemization catalyst.

Scheme 1. Preparation of the Immobilized Racemization Catalyst, SCRAM, 1

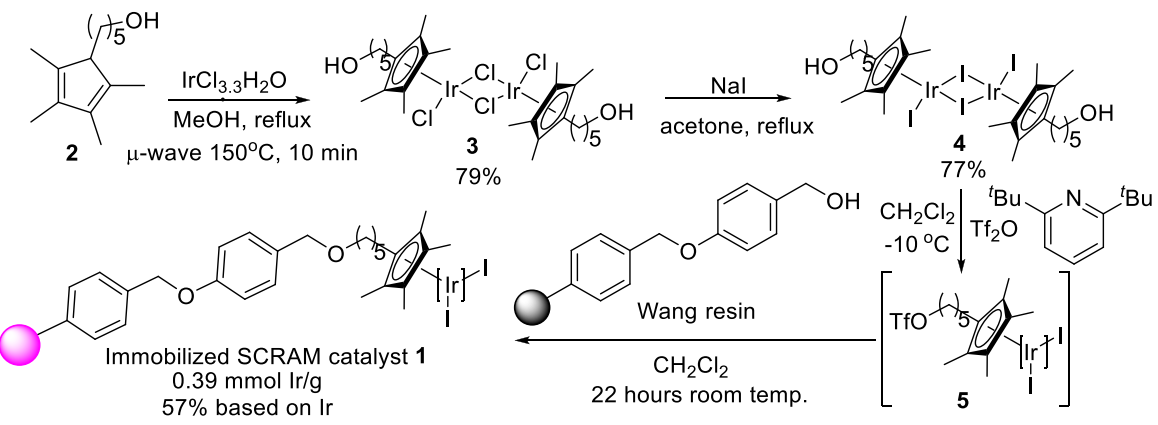

required space group and have easily racemizable chiral centers. ${ }^{19-21}$ CIDT involves establishing a dynamic thermodynamic equilibrium between the salts epimerizing in solution and crystallization of the less soluble diastereomer. The equilibrium adjusts by dissolution of the more soluble diastereomer and results in a higher yield of the resolved solid, Figure $1 .^{22}$ Each of these techniques requires compounds that racemize easily under resolution conditions, relying on substrates with an acidic or enolizable chiral proton. However, racemization and resolution processes compete, with the former being faster at higher temperatures while the latter operated preferably under ambient conditions. This limitation can be overcome by continuously flowing the soluble reactants across a solid supported, heated, racemization catalyst and cooling back for the resolution. Furthermore, when kept separate, interference between the resolution and racemization is avoided, and the product is more easily separated from the catalyst.

A way to increase the scope of amine racemizations beyond those that rely on acidic, tautomerizable chiral centers is to employ hydrogen transfer catalysts which are able to dehydrogenate unactivated amines. Heterogenous amine racemization catalysts such as $\mathrm{Pd} / \mathrm{C}$ or $\mathrm{Pd} / \mathrm{BaSO}_{4}$ lend themselves well to this but can suffer poor activity and selectivity. ${ }^{23,24}$ A variety of homogeneous catalysts are known to borrow and replace the proton at the chiral center of secondary alcohols; however, few have been identified that perform a similar hydrogen transfer reaction with chiral amines. ${ }^{25}$ Catalysts that have proven effective in this regard are the ruthenium based Shvö and analogues ${ }^{26}$ and iodoiridium, SCRAM. ${ }^{16}$ The former is better able to racemize primary amines, and the latter, secondary and tertiary chiral amines. This is because the iridium center coordinates and activates primary imines toward $N$-alkylation, resulting in dimerization. ${ }^{27}$ Both of these homogeneous catalysts have been used in enzymatic DKR of amines but not in CIDT. ${ }^{28-30} \mathrm{~A}$ silica-supported Shvö catalyst has been reported recently for the transfer hydrogenation of levulinic acid ${ }^{31}$ but is not reported for racemization. Similarly, a polymer supported chloro-iridium catalyst, tethered by a functionalized $\mathrm{Cp}^{*}$ ligand, is reported for the reduction of benzaldehyde and repeated reuse. ${ }^{32}$ The same supported metal, modified with chiral ligand, has shown a long lifetime in the continuous flow asymmetric transfer hydrogenation of ketones. ${ }^{33}$

There are several ways in which a combined resolution and racemization can be configured. A DKR example reported by Falus et al. uses solid supported subtilisin enzyme to resolve an amine by esterifying selectively one enantiomer. ${ }^{34}$ The mixture, containing the remaining alcohol enantiomer, is flowed across a fixed-bed racemization catalyst and the sequence repeated across 10 columns to give the amide in $98 \%$ e.e. and $79 \%$ yield with productivity of $8 \mathrm{~g} / \mathrm{L} / \mathrm{h}$ running over a week. In another example, de Miranda et al. packed into one column layers of solid-supported CalB lipase (to resolve phenethyl alcohol) and $\mathrm{VOSO}_{4}$ (to racemize the unreacted alcohol enantiomer) using toluene at $70{ }^{\circ} \mathrm{C} .{ }^{35}$ Four resolution and three racemizing layers were enough to generate the product in $90 \%$ e.e. and $82 \%$ yield. To avoid sequential columns, each separately supported 


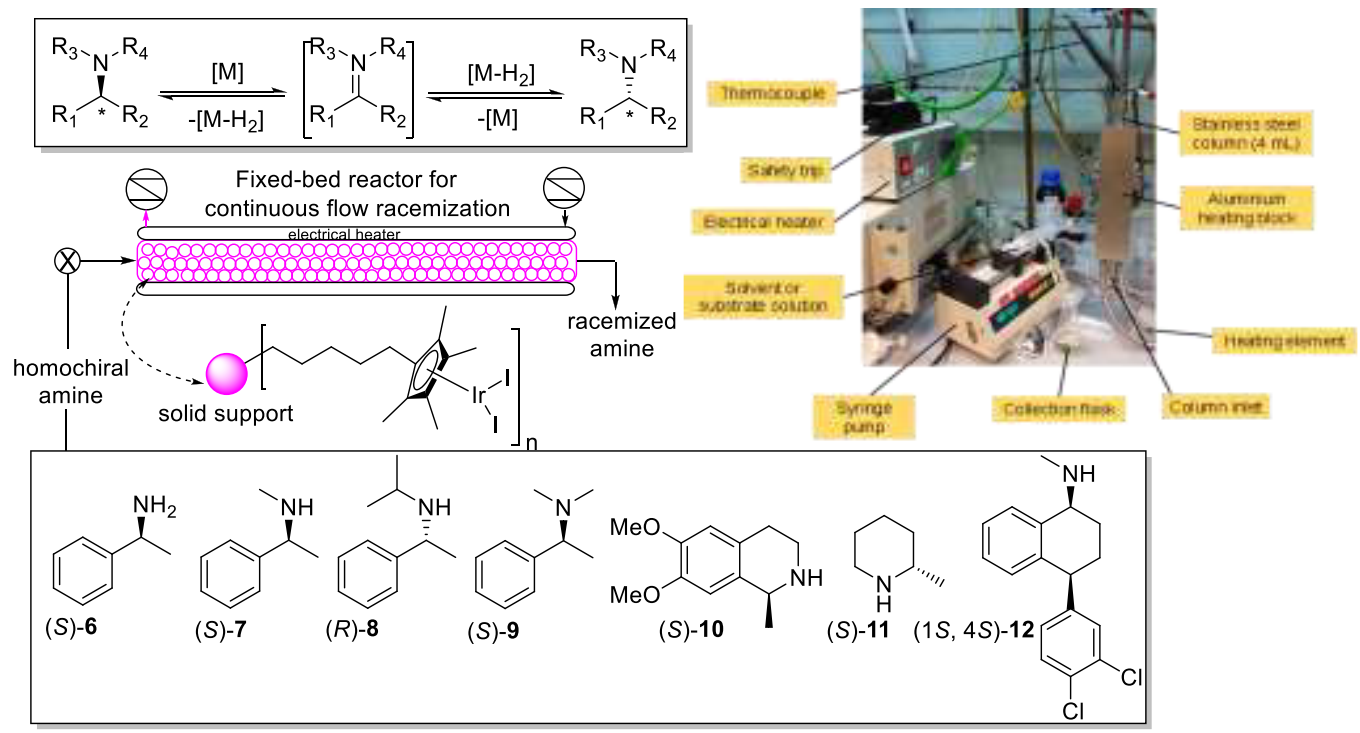

Figure 2. Scheme and setup for continuous flow racemization of amines 6-12.

Table 1. Continuous Flow Racemization of Chiral Amines

\begin{tabular}{|c|c|c|c|c|c|c|c|}
\hline entry & amine $^{a}[\mathrm{mM}]$ & solvent(s) (ratio) & $\begin{array}{c}\text { Ir loading }^{b} \\
(\mathrm{~mol} \mathrm{\%})\end{array}$ & $\begin{array}{l}\text { temp } \\
\left({ }^{\circ} \mathrm{C}\right)\end{array}$ & $\begin{array}{l}\text { racemization at steady state } \\
\left(\text { e.e. } \min ^{-1}\right)\end{array}$ & $\begin{array}{c}t_{\text {Res }} \\
(\mathrm{min})\end{array}$ & $\begin{array}{l}\mathrm{TOF}^{\mathrm{c}} \\
\left(\mathrm{h}^{-1}\right)\end{array}$ \\
\hline 1 & $(S)-6[100]$ & toluene/DTBP ${ }^{d}(1: 1)$ & 5 & 105 & $0.4^{e}$ & 16 & 0.25 \\
\hline 2 & $(S)-7[100]$ & ${ }^{i} \mathrm{PrOAc}$ & 5 & 80 & $2.87^{f}$ & 15 & 34.8 \\
\hline 3 & $(S)-7[100]$ & $\mathrm{EtOAc} / \mathrm{MeOH}(4: 1)$ & 5 & 73 & 1.17 & 12 & 14.4 \\
\hline 4 & $(R)-8[50]$ & $\mathrm{EtOCO}^{i} \mathrm{Bu}^{g}$ & 10 & 80 & 0.47 & 30 & 2.80 \\
\hline 5 & $(S)-9[50]$ & ${ }^{i} \mathrm{PrOAc} /{ }^{i} \mathrm{PrOH}(7: 3)$ & 10 & 80 & 0.37 & 30 & 2.20 \\
\hline 6 & $(S)-10[62]$ & $\mathrm{EtOAc} / \mathrm{MeOH}(7: 1)$ & 10 & 60 & 37.8 & 2.25 & 227 \\
\hline 7 & $(R / S)-\mathbf{1 0}-(S)-\mathbf{M A}^{h}[64]$ & $\mathrm{EtOAc} / \mathrm{MeOH}(7: 1)$ & 10 & 60 & $4.3^{i, j}$ & 6 & 25.8 \\
\hline 8 & $(S)-11[80]$ & $\mathrm{MTBE} /{ }^{i} \mathrm{PrOH}(95: 5)$ & 5 & 50 & 0 & 4.5 & 0 \\
\hline 9 & $(S)-\mathbf{1 1}[100]$ & ${ }^{i} \mathrm{PrOAc}$ & 5 & 80 & 13.17 & 6 & 158 \\
\hline 10 & $(1 S, 4 S)-12[500]$ & toluene & 1 & 80 & $4.2^{i}$ & 15 & 252 \\
\hline
\end{tabular}

${ }^{a}$ Synthesis and characterization described in the Experimental Section and Supporting Information. Bracketed values are feed concentrations. ${ }^{b}$ Relative to the total amount of amine pumped across the catalyst. ${ }^{c}$ Average taken over $2-3 \mathrm{RV}$. Defined in the Supporting Information. ${ }^{d} 2,4-$ Dimethylpentan-3-ol. ${ }^{e}$ While racemizing, most of the amine decomposed to other species. ${ }^{f^{3}}$ The initial e.e. of $(S)-7$ was $86 \% .{ }^{g}$ Ethyl iso-butyrate. ${ }^{h}$ Mandelic acid. ${ }^{i}$ D.e. ${ }^{j}$ The initial d.e. was $38 \%$.

catalyst can be intimately mixed; however, thermal control of each is then lost. Nevertheless, Farkas et al. achieved high e.e.'s and conversion in the DKR of benzylic primary amines using a supported CalB lipase and palladium-based hydrogen transfer catalyst. $^{36}$ Another operational mode is to continuously recirculate the solution between resolution and racemization, though this appears not to have been evaluated for dynamic crystallizations. This involves separating crystals from mother liquors and racemizing and recirculating them. The work described here starts by preparing an immobilized iodo-iridium racemization catalyst $\mathbf{1}$, exploring its use in continuous flow racemization, and then integrating this with diastereomeric crystallization to give the resolution-racemization-recycle $\mathrm{R}^{3}$ process.

\section{RESULTS AND DISCUSSION}

Continuous Flow Racemization. The immobilized SCRAM catalyst, 1, was prepared as described previously, ${ }^{32}$ by reacting the homogeneous chloro-iridium $\mathrm{Cp}^{*} \mathrm{C}_{5} \mathrm{OH}$ complex 3 first with excess sodium iodide to exchange the halide for an iodo-ligand, 4, and then activating the alcohol by triflation to make 5, which was reacted in situ with Wang resin,
Scheme 1. After thorough washing of the beads, the amount of iridium supported on the resin was found by ICP to equate to $0.39 \mathrm{mmol}$ of $\mathrm{Ir} / \mathrm{g}$.

To integrate the racemization and resolution processes, it is necessary to have a common solvent. It was found that the immobilized catalyst $\mathbf{1}$ is active in most solvents, except dipolar aprotics that may coordinate to the metal. This is convenient, because the selection of crystallization solvent is critical to the efficiency of the diastereomeric resolution. Solvents that are preferred for both steps maximize the difference in solubility between the diastereomeric salts and have a high enough boiling point to increase the racemization rate, but below 120 ${ }^{\circ} \mathrm{C}$, the point at which the polymer support breaks down. It was shown that alcoholic solvents, that act as hydrogen donors, are useful cosolvents, as they can increase the rate of racemization by enhancing imine reduction and reduce sidereactions. ${ }^{37}$ Racemization in continuous flow was tested with optically pure amines 6-12, Figure 2.

A mass of immobilized catalyst 1 , sufficient to give 5-10 mol \% iridium loading, was mixed with washed sand, to manage swelling and compaction, and packed into an empty 4 $\mathrm{mL}, 23 \mathrm{~cm}$ HPLC column. The reactor's fluid volume was 


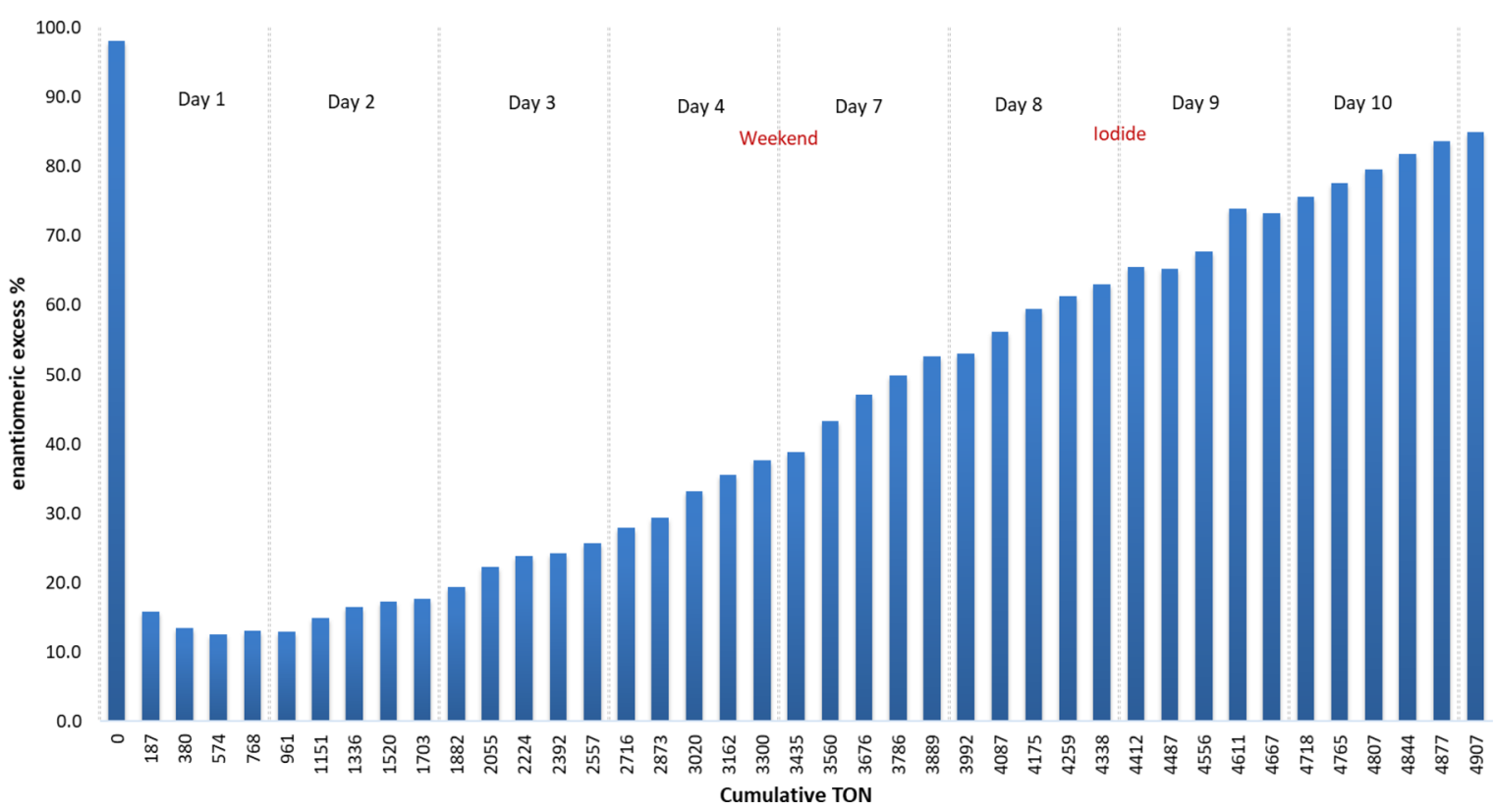

Figure 3. Gradual deactivation of catalyst 1 during 10 days of intermittent flow of amine (S)-7.

measured by solvent mass difference as $1.5 \mathrm{~mL}$. The column was placed in an electrically heated aluminum block, and amine solution was pumped at a temperature and flow rate enough to cause a significant amount of racemization in a short residence time. Table 1 shows the results of continuous flow racemization of optically pure amines 6-12 at steady state (Supporting Information section 7), measured as the fall in e.e. per minute and converted to turnover frequency (TOF) per hour.

The primary amine $(S)-6$ is racemized slowly, entry 1 , the reason being that side-reactions associated with the intermediate imine cause liberation of ammonia that deactivates the catalyst. An attempt to suppress the side reactions by adding the hindered hydrogen donor 2,4-dimethylpentanol 50\% (v/v) was of limited success. ${ }^{30}$ Benzylic amines $(S)-7$ to $(S)-9$ racemized with rates of $0.37-2.87 \%$ e.e. $/ \mathrm{min}$ at steady state. With flow rates adjusted to give residence times of 12-30 min, racemizations of 43,14 , and $11 \%$ ee for $(S)-7,(S)-8$, and $(S)$ 9 , respectively, were achieved in one pass, entries 2,4 , and 5 . The TOFs of 1 are significantly less than the homogeneous catalyst $\left[\operatorname{IrCp} * I_{2}\right]_{2}$ used with these substrates in batch (Supporting Information section 7); however, this is compensated using 5-10 mol \% of $\mathbf{1}$. A 10-day continuous flow racemization was performed on $(S)-7$ to determine the impact of catalyst deactivation on extended use, Figure 3.

On day 1 , the e.e. reached steady state after two to three vials, falling from $98 \%$ (stock solution) to $12.5 \%$ ee. Thereafter, the activity of the catalyst fell almost linearly at $2.8 \%$ e.e. $/ \mathrm{h}$, until after 10 days the amine was only racemized by $13 \%$ e.e, with a TON of 30 compared with 187 at the start. Nevertheless, the cumulative TON was 4907, showing an effective catalyst use of $0.02 \mathrm{~mol} \%$. The cause of deactivation has been determined as methylamine coordination to the iridium which arises from hydrolysis of the imine intermediate. $^{38}$ Reducing the moisture content or adding isopropanol hydrogen donor reduces but does not eliminate the catalyst deactivation. The addition of potassium iodide at day 9 had little effect on reversing the inhibition; however, it was found that treating the spent catalyst with dilute hydroiodic acid $(0.1 \mathrm{M})$ for $2 \mathrm{~h}$ recovered about $25 \%$ of the activity. More concentrated acid or extended exposure led to cleavage of the catalyst from the resin. Unfortunately, this reactivation procedure is tedious and requires extensive washing to remove the acid. As it was only partially successful, emptying and repacking the fixed bed using fresh catalyst was adopted instead.

Salsolidine $(S)$-10 was racemized at $37.8 \%$ e.e. $/ \mathrm{min}$, so a residence time $\left(t_{\text {res }}\right)$ of 2.25 min gave a fall of $85 \%$ e.e., entry 6 . The same packed column of catalyst was reused in different experiments 130 times, giving a total TON of 1105. The mother liquor solution derived from the diastereomeric crystallization of $\mathbf{1 0}$ with $(S)$-mandelic acid $((S)$-MA) gave a reduced TOF of $25.8 \mathrm{~h}^{-1}$; nevertheless, in a single pass, or 1 reactor volume, the catalyst was able to epimerize the diastereomer by $26 \%$ d.e., indicating that continuous racemization of crystallization mother liquor (ML) would be feasible, entry 7 . The possibility that the epimerization was caused by racemization of $(S)$-MA, or the mandelate anion, rather than the amine, was tested by stirring $(S)$-MA or its mandelate salt with catalyst $\mathbf{1}$ in batch under the same conditions as entry 7. Neither of them showed any racemization. However, after $12 \mathrm{~h}, 3.5 \%$ phenylglyoxalate was formed from the mandelate salt by dehydrogenation of the alcohol group. Since epimerization of the diastereomeric salt involves only the amine, the process is hereinafter described as racemization. Surprisingly, the racemization of heterocyclic amine (S)-11 failed when methyl tert-butyl ether (MTBE) and iso-propyl alcohol were used, entry 8. However, iso-propyl acetate solvent worked well, giving a racemization rate of $13.2 \%$ e.e./min with a catalyst TOF of $158 \mathrm{~h}^{-1}$, entry 9 . The continuous flow epimerization of sertraline $(1 S, 4 S)-12$ in toluene at $80{ }^{\circ} \mathrm{C}$ was successful with a catalyst TOF of $252 \mathrm{~h}^{-1}$, though over 9 reaction volumes the activity fell by half. As with amine 7, a linear deactivation of the catalyst was found with $\mathbf{1 2}$, at a rate of $14 \%$ d.e./ $h$ which is also caused by methylamine. ${ }^{38}$

Development of a Resolution-Racemization-Recycle Process. With a continuous flow racemization method in hand, we sought to integrate this with the diastereomeric 
crystallization. Direct addition of the homogeneous SCRAM catalyst to the crystallization was unsuccessful because the racemization rates were too low at ambient temperature. Furthermore, the homogeneous catalyst interfered with the crystallization (the crystals formed were dark rather than white solids) and made purification of the product more difficult. This provided the rationale for the recycle system using immobilized catalyst 1 . An important consideration was the acidity of the system, as carboxylic acids are known to retard hydrogen transfer by reacting with the iridium hydride intermediate to form dihydrogen (hence the use of triethylammonium formate as hydrogen donor rather than formic $\left.\operatorname{acid}^{39}\right)$. It was already shown that $\mathbf{1}$ was active in racemizing the diastereomeric salt, Table 1 , entry 7 , and that $(S)$-MA salt was insensitive to racemization. To ensure a neutral or basic solution, a slight under-charge of the resolving acid was used at the start of the work; however, it was later shown as unnecessary and a 1:1 stoichiometry was satisfactory. The equipment used to integrate the resolution, racemization, and recycle steps is shown in Figure 4.

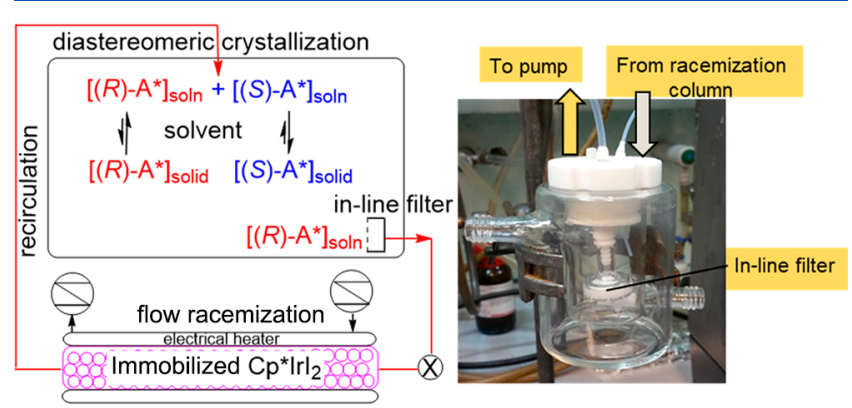

Figure 4. Schematic of the $\mathrm{R}^{3}$ process, with solid retained in the crystallizer by an in-line filter (photograph). The enantiomerically enriched solution is pumped across the heated fixed bed of iodoiridium racemization catalyst, and the racemized solution is recirculated back to the crystallizer where more of the less soluble diastereomer can form.

A temperature-controlled crystallizer with gas-tight PTFE lid, drilled with holes to support the in- and outflow tubes, is gently stirred with a magnetic stirrer bar, and the system is a closed loop. Solutions of the acid and amine were introduced in a solvent at a concentration enough to cause precipitation of solid. The solubility of each diastereomer was measured to facilitate selection of the optimal concentration. The mother liquors, that are enriched with the more soluble diastereomer, were separated from the solid using a sintered glass in-line filter that pumped the saturated solution into the electrically heated racemization column. The hot outflow is now enriched in the less soluble diastereomer and subsaturated in the more soluble one. As the solution is returned to the crystallizer, it becomes supersaturated in the less soluble diastereomer which further crystallizes. This happens as the more soluble diastereomer dissolves, thus providing a dynamic equilibrium, Scheme 2.

The scope of the system was tested with $(S)$-MA salts of amines 7-11, Table 2, entries 1-10. The poor results with amines 7 and 9 prompted us to use $(S, S)$-ditoluoyl tartaric acid ((S,S)-DTTA) instead, entries 11-14.

The solvent and substrate concentrations were selected from those that gave a substantial amount of solid in batch at ambient temperature. The yield of solid produced during the reaction was inferred by subtracting the concentration of
Scheme 2. Proposed Mechanism for the Formation of the Predominant Diastereomer

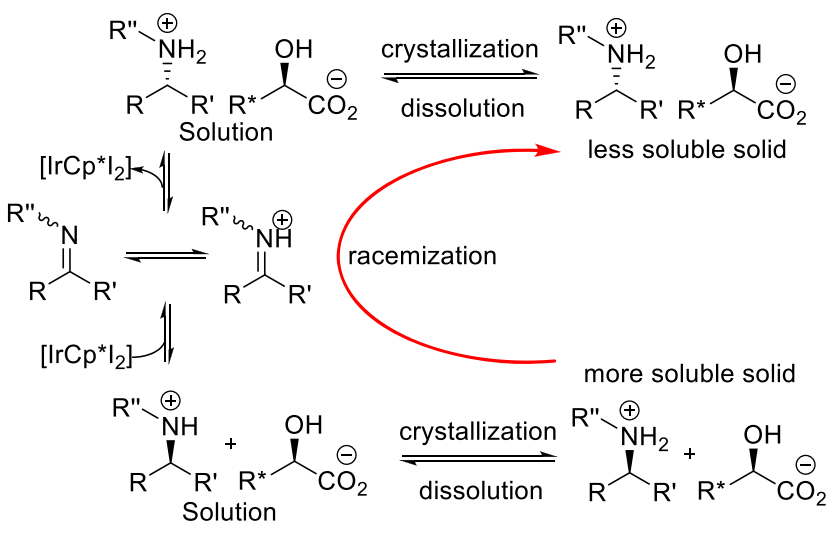

soluble amine (and derived impurities) from the initial amount using calibrated GC. The d.e. was measured from a sample of the solid, dried, and dissolved in solvent for analysis by chiral HPLC, ${ }^{1} \mathrm{H}$ NMR, or GC to determine the e.e. of the free amine generated from the salt. The solubility of each pure diastereomer was measured by analyzing its saturated solution in the corresponding solvent. It is useful to compare the performance of the batch and $\mathrm{R}^{3}$ processes; however, yield and d.e. can be competing functions and determining optimum conditions can be time-consuming. Resolvability, $S$, is the product of both variables and can be useful to compare outcomes. In a perfect batch resolution, $S_{\max }=1.0$, i.e., $2 \times$ $50 \%$ yield $\times 100 \%$ d.e., and in a dynamic system, $S_{\max }=2.0$. ${ }^{40}$ The resolvability of 7-(S)-MA was found to be the same in batch diastereomeric crystallization as the $\mathrm{R}^{3}$ process, $S=0.36$, Table 2, entries 1 and 2; however, the solid yield is $30 \%$ with $60 \%$ d.e. in the $\mathrm{R}^{3}$ process but $49 \%$ yield with $37 \%$ d.e. in batch. Acetophenone, formed by hydrolysis of the intermediate imine, was seen to accumulate slowly over $190 \mathrm{~h}$ to about $10 \%$ of the reaction mass. Since methylamine is a potent catalyst inhibitor, catalyst activity was assayed at the end of the experiment and was $42 \%$ less active than at the start. Nevertheless, this does not explain the low solid yield in the $\mathrm{R}^{3}$ process; rather, this indicates a change in crystallinity, perhaps because of the impurities or crystal growth inhibition. A different resolving reagent gave better results, entries 11 and 12 , but also exposed some unusual behaviors that are discussed later.

There is a large difference in the solubilities of the 8-(S)-MA diastereomers, which provides a good driving force for the dynamic resolution, Table 2 , entries 3 and 4 . The $R^{3}$ process was run at a flow rate of $0.1 \mathrm{~mL} / \mathrm{min}$, giving a recycle time of 4.75 h. The d.e. steadily increased to $89 \%$ after 30 recycles with an isolated solid yield of $62 \%$, Figure 5 .

The concentration and e.e. of amine $\mathbf{8}$ in the mother liquors (MLs) fell gradually over the course of the experiment. However, the rate of fall does not correlate with the solid, indicating that the rate-limiting step may be the growth or dissolution of the solid, not racemization. It would be interesting to determine these parameters, as the effect of constant supersaturation of one diastereomer and subsaturation of the other may be different from those in the batch diastereomeric crystallization. The resolvability of amine $\mathbf{8}$ was improved to $S=1.1$, compared with the batch diastereomeric crystallization $S=0.67$. Based on the measured solubilities, the 
Table 2. Comparison of the Resolvability of Four Amine Salts in Batch with the $\mathrm{R}^{3}$ Process

\begin{tabular}{|c|c|c|c|c|c|c|c|c|}
\hline entry & product & solvent & $\begin{array}{l}\text { solubility } \\
(\mathrm{mg} / \mathrm{mL})\end{array}$ & $\begin{array}{c}\text { resolvability }^{a} \text { in } \\
\text { batch }\end{array}$ & $\begin{array}{l}\text { no. of recycles } \\
\text { (h) }\end{array}$ & $\begin{array}{c}\text { yield }^{b} \\
(\%)\end{array}$ & $\begin{array}{l}\text { d.e. }^{c} \\
(\%)\end{array}$ & $\begin{array}{c}\text { resolvability }^{a} \mathrm{R}^{3} \\
\text { process }\end{array}$ \\
\hline 1 & $(S)-7-(S)-\mathbf{M A}$ & ${ }^{i} \operatorname{PrOAc}$ & 25.2 & $0.36^{d}$ & $40(190)$ & 30 & 60 & 0.36 \\
\hline 2 & (R)-7-(S)-MA & ${ }^{i} \operatorname{PrOAc}$ & 3.6 & & & & & \\
\hline 3 & $(S)-\mathbf{8}-(S)-\mathbf{M A}$ & $\mathrm{EtOCO}^{i} \mathrm{Bu}^{e}$ & 145 & $0.67^{f}$ & $30(142)$ & 62 & 89 & 1.10 \\
\hline 4 & $(R)-8-(S)-\mathbf{M A}$ & $\mathrm{EtOCO}^{i} \mathrm{Bu}^{e}$ & 0.3 & & & & & \\
\hline 5 & $(S)-\mathbf{9}-(S)-\mathbf{M A}$ & ${ }^{i} \operatorname{PrOAc}$ & $>43$ & $\mathrm{~N} / \mathrm{A}$ & $\mathrm{N} / \mathrm{A}$ & $\mathrm{N} / \mathrm{A}$ & $\mathrm{N} / \mathrm{A}$ & $\mathrm{N} / \mathrm{A}$ \\
\hline 6 & $(R)-9-(S)-\mathbf{M A}$ & ${ }^{i} \mathrm{PrOAc}$ & $>43$ & & & & & \\
\hline 7 & $(S)-\mathbf{1 0}-(S)-\mathbf{M A}$ & EtOAc $/{ }^{i} \mathrm{PrOH}^{g}$ & 3.0 & $0.11^{h}$ & $8(6.7)$ & 65 & 96 & 1.25 \\
\hline 8 & $(R)-10-(S)-\mathbf{M A}$ & $\mathrm{EtOAc} /{ }^{i} \mathrm{PrOH}^{g}$ & 0.7 & & & & & \\
\hline 9 & $(S)-11-(S)-\mathbf{M A}$ & ${ }^{i} \mathrm{PrOAc}$ & 7.5 & $0.11^{i}$ & $16(30)$ & 52 & 89 & 0.93 \\
\hline 10 & $(R)-\mathbf{1 1}-(S)-\mathbf{M A}$ & ${ }^{i} \operatorname{PrOAc}$ & 2.4 & & & & & \\
\hline 11 & {$[(S)-7]_{2}-(S, S)$-DTTA } & $\mathrm{EtOAc} /{ }^{i} \mathrm{PrOH}^{g}$ & 0.2 & $0.03^{j}$ & $35(166)$ & 78 & 86 & 1.34 \\
\hline 12 & {$[(R)-7]_{2}-(S, S)$-DTTA } & $\mathrm{EtOAc} /{ }^{i} \mathrm{PrOH}^{g}$ & 0.9 & & & & & \\
\hline 13 & {$[(S)-9]-(S, S)$-DTTA } & $\mathrm{EtOAc} / \mathrm{EtOH}^{k}$ & 9.5 & $0.49^{l}$ & $17(242)$ & 17 & 77 & 0.26 \\
\hline 14 & {$[(R)-9]-(S, S)$-DTTA } & $\mathrm{EtOAc} / \mathrm{EtOH}^{k}$ & 44.1 & & & & & \\
\hline
\end{tabular}

${ }^{a}$ Resolvability, $S=2 \times$ yield $\times$ d.e. ${ }^{b}$ Isolated molar yield of diastereomeric solid based on $100 \%$ amine. ${ }^{c}$ D.e. determined by ${ }^{1} \mathrm{H} \mathrm{NMR}$ (in $\mathrm{CDCl}_{3}$ ), chiral HPLC, or chiral GC (on the free amine). ${ }^{d} 49 \%$ yield, $37 \%$ d.e. ${ }^{e}$ Ethyl iso-butyrate. ${ }^{f} 48 \%$ yield, $70 \%$ d.e. ${ }^{g} 7: 1$ (v/v). ${ }^{h} 80 \%$ yield, $7 \%$ d.e. ${ }^{i} 53 \%$ yield, $20 \%$ d.e. ${ }^{j} 84 \%$ yield, $2 \%$ d.e.; measured at 6 h. ${ }^{k} 7: 3$ (v/v). ${ }^{l} 42 \%$ yield, $59 \%$ d.e.

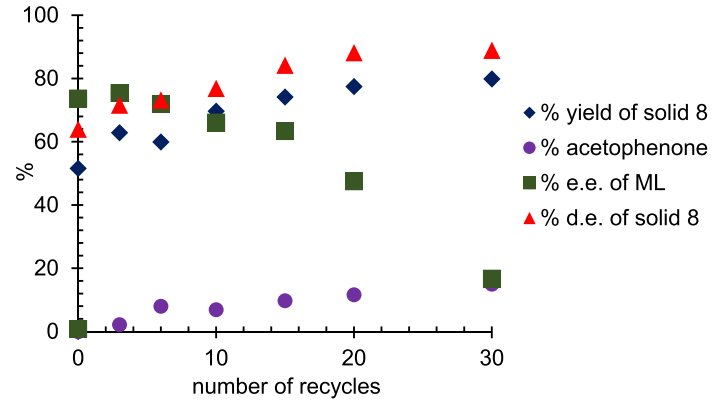

Figure 5. Resolution of racemic amine $\mathbf{8}$ with $(S)$-MA using the $\mathbf{R}^{3}$ process.

predicted yield is $80 \%$, while the isolated yield was $62 \%$; the difference is due mainly to formation of acetophenone (16.7\%).

Resolution of amine 9 using $(S)$-MA failed, as the diastereomeric salts failed to crystallize in any of the solvents tested; in iso-propyl acetate, the solubility at ambient temperature exceeded $43 \mathrm{mg} / \mathrm{mL}$, entries 5 and 6 . Instead, the diacid resolving reagent $(S, S)$-DTTA was tried with results discussed later, entries 13 and 14 .

Racemic 1-methyl tetrahydro-iso-quinoline $\mathbf{1 0}$ forms diastereomeric salts easily with $(S)$-MA, and a solvent composition of ethyl acetate and iso-propanol $(7: 1 \mathrm{v} / \mathrm{v})$ was found to give a high d.e. solid at ambient temperature, Table 2, entries 7 and 8. The batch diastereomeric crystallization gave $80 \%$ yield and $7 \%$ d.e., $S=0.11$; however, the $\mathrm{R}^{3}$ process gave a resolvability of $S=1.25$. Figure 6 shows the reaction profile with change in solid yield, d.e., and impurities over 30 recycles; each recycle was $48 \mathrm{~min}$, at a flow rate of $0.5 \mathrm{~mL} / \mathrm{min}$.

After one recycle, $83 \%$ of the amine forms a solid and this remains relatively constant; however, the initial $44 \%$ d.e. drops to $17 \%$ after one racemization recycle and then slowly rises over the next 30 recycles $(24 \mathrm{~h})$ to finish at $96 \%$ d.e. The improved performance of $\mathrm{R}^{3}$ was encouraging, but a limitation identified was that the yield of the solid is determined by the solubility of the least soluble diastereomer. The solubility of both diastereomers was measured as 3.0 and $0.7 \mathrm{mg} / \mathrm{mL}$. This 4.3-fold difference explains the driving force on the dynamic

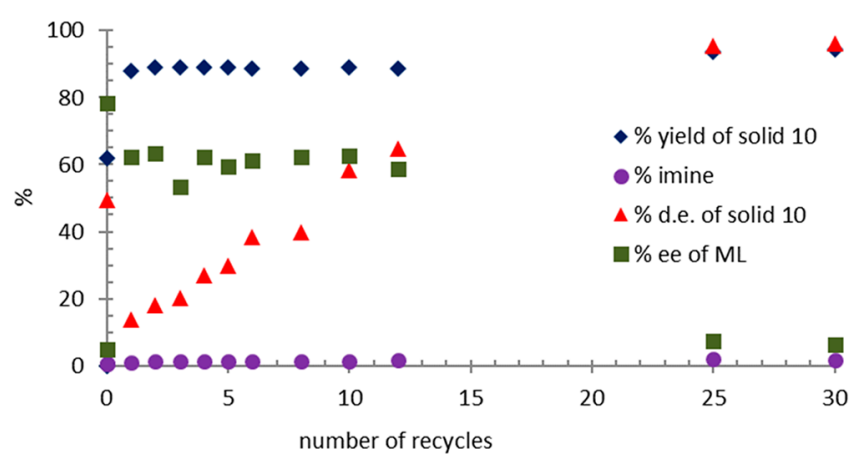

Figure 6. Resolution of racemic amine 10 with (S)-MA and continuous racemization of the mother liquors showing initial formation of solid and its gradual increase in d.e. with recycle.

equilibrium but also that $9 \%$ of the mass remains in solution, giving a theory maximum yield of $91 \%$, versus the $86 \%$ yield observed. The remaining mass is the side-reaction impurities dihydro- and iso-quinoline resulting from transfer dehydrogenation. However, they remained at low levels using iso-propanol as a hydrogen donor which serves to reduce them back into $\mathbf{1 0}$.

When $(S)$-MA was added to racemic amine $\mathbf{1 1}$ in batch, 53\% solid of $20 \%$ d.e. formed immediately, Table 2, entries 9 and 10. Applying these conditions to the $\mathrm{R}^{3}$ process, a flow rate of $0.25 \mathrm{~mL} / \mathrm{min}$ gave a recycle time of $114 \mathrm{~min}$ and racemization residence time of $6 \mathrm{~min}$ at $80{ }^{\circ} \mathrm{C}$. The resolvability in the $\mathrm{R}^{3}$ process was $S=0.93$ compared to $S=0.11$ in batch, with the solid d.e. improved from 20 to $89 \%$ but little change in yield. The solubility of both diastereomers was determined as 7.5 and $2.4 \mathrm{mg} / \mathrm{mL}$, giving a theoretical yield of $61 \%$ solid versus $52 \%$ isolated. A yellow colored impurity formed during racemization was tentatively assigned by MS as a trimeric species. ${ }^{41} \mathrm{~A}$ similar trend was observed with d.e. increasing with time, reaching $89 \%$ after 16 recycles $(30 \mathrm{~h})$, Figure 7.

The e.e. and concentration of the amine in the mother liquors fell gradually, though at a higher rate than the solid, perhaps indicating crystal growth or dissolution as rate limiting. The activity of the catalyst was determined at the end of the experiment and had the same TOF as at the start, 


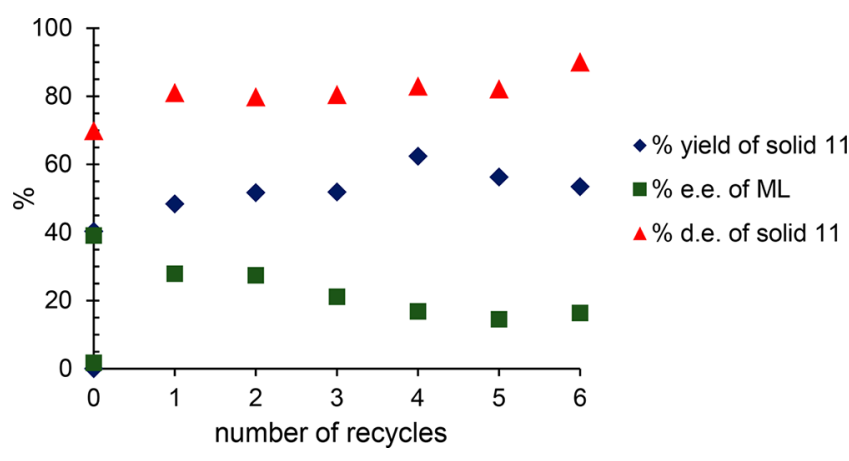

Figure 7. Resolution of racemic amine 11 with (S)-MA and continuous racemization of the mother liquors.

though after two further runs of similar duration it was found to have lost half of its activity.

To improve the resolution of amine 7 , a half mole equivalent of chiral acid, $(S, S)$-DTTA, was tested, Table 2, entries 11 and 12. Using ethyl acetate with $20 \%(\mathrm{v} / \mathrm{v})$ iso-propanol, an insoluble precipitate was isolated after $6 \mathrm{~h}$ in $84 \%$ yield. Analysis indicated a 2:1 amine:acid salt of only $2 \%$ d.e. The diastereomeric crystallization was carried out in the presence of homogeneous SCRAM catalyst in a one-pot recycle system. The concentration of amine 7 in solution and d.e. of the solid remained at 66 and 75\%, respectively, for about $25 \mathrm{~h}$. Surprisingly, a sample taken after $30 \mathrm{~h}$ revealed a significant drop of concentration of 7 in solution to $<40 \%$ and the d.e. of the solid decreased to about $6 \%$. ${ }^{1} \mathrm{H}$ NMR analysis of the DTTA showed no epimerization, and the 2:1 stoichiometry of the salt was the same. The same system was tested in batch without racemization and was sampled with time. It was found that the initial d.e. of the solid formed was $70 \%$ but fell to $6 \%$ over $6-12$ h, Figure 8.

Crystals taken at the start and end of the experiment were analyzed by powder and single crystal X-ray diffraction, Figure 8. It was found that a switch in amine enantiomers within the solid phase had occurred, going from the $[(S)-7]_{2}-(S, S)$-DTTA diastereomer to a, presumably more stable, meso-like form $[(S)-7][(R)-7]-(S, S)$-DTTA containing a racemate of both amine enantiomers, hence the observed fall in d.e. The experiment was repeated twice with similar results. Ferreira et al. have observed this behavior previously with $\operatorname{rac}-6-(S, S)$ DTTA, and they developed a model to explain the different solid forms that were related to solubility, acid:amine ratio, and
$\mathrm{pH}^{42}$ The unusual switch in solid form was investigated further, Figure 9.

Figure 9a shows that the higher the temperature, the more rapid the switch from $[(S)-7]_{2}-(S, S)$-DTTA to $[(S)-7][(R)-7]$ $(S, S)$-DTTA, which may be related to increased mass transfer and nucleation rate. Figure $9 \mathrm{~b}$ shows that a 2:1 stoichiometry of the amine and diacid is required, and with only a quarter equivalent of $(S, S)$-DTTA to $(S)-7$, the $[(S)-7]_{2}-(S, S)$-DTTA diastereomeric salt remains stable over $36 \mathrm{~h}$. Figure 9c illustrates that higher concentrations of $(S)-7$ cause a faster rate of switching at the same 2:1 amine/acid stoichiometry, presumably because of an increased nucleation rate. Similarly, higher rates of mixing cause more crystal attrition and are likely to increase the $[(S)-7][(R)-7]-(S, S)$-DTTA nucleation rate, Figure $9 \mathrm{~d}$. This is confirmed when seeds of $[(S)-7][(R)-7]$ $(S, S)$-DTTA are added to the system and the more stable diastereomer is formed more rapidly over $5 \mathrm{~h}$, whereas the seeds of $[(S)-7]_{2}-(S, S)$-DTTA have no effect on the switching time compared to the control, Figure 9e. In the $\mathrm{R}^{3}$ process of amine $7,0.25$ equiv of $(S, S)$-DTTA was first added to form solely the less soluble $(S)-7-(S, S)$-DTTA- $(S)-7$ first. The remaining 0.25 equiv of $(S, S)$-DTTA was added slowly to allow enough time for $(R)-7$ to racemize to $(S)-7$ so as to lower the concentration of $(R)-7$ in the system, hence avoiding the switching to $(S)-7-(S, S)$-DTTA- $(R)-7$, Table 2 , entries 11 and 12. A resolvability of 1.34 was achieved, a 44-fold improvement compared to diastereomeric resolution alone. It is interesting to speculate whether other diastereomeric crystallizations that employ diacids might be susceptible to this effect: initially, the diastereomer is formed under kinetic control, giving a metastable product, and with time, a more stable crystal morphology is formed. When resolving reagents and conditions are screened, samples are rarely taken over time, so a low d.e. will be dismissed as a failure. Though of little practical use, as no resolution is achieved, the thermodynamic phenomenon appears to be the opposite of CIAT that is under kinetic control.

Unlike amine 7, the $N, N$-dimethyl analogue 9 forms a $1: 1$ rather than 2:1 salt with $(S, S)$-DTTA, using either 0.5 or 1 equiv of the diacid. A solvent screen was carried out and ethyl acetate-ethanol $(7: 3)$ gave the best yield $(42 \%)$ and d.e. (59\%) with $S=0.49$, Table 2 , entries 13 and 14 . Since the racemization of 9 was found to be slow, a residence time of 2.5 $\mathrm{h}$ was selected as well as a whole process recirculation time of $14.3 \mathrm{~h}$. At the start, a gradual increase in d.e. of the solid was
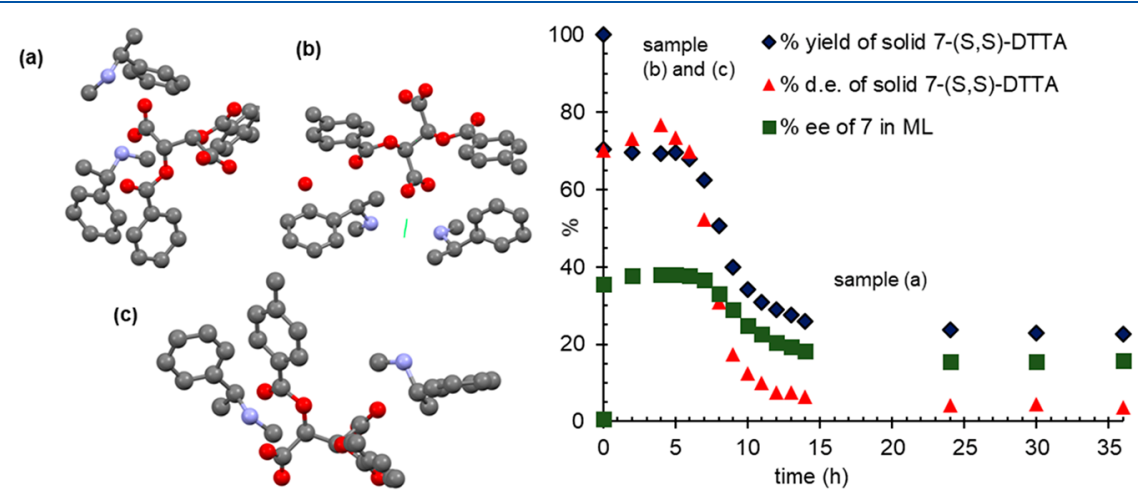

Figure 8. Left: X-ray crystal structures of (a) $[(S)-7]_{2}-(S, S)$-DTTA, (b) $[(R)-7]_{2}-(S, S)$-DTTA, and (c) $[(S)-7][(R)-7]-(S, S)-D T T A$. The hydrogen atoms are omitted for clarity. The nitrogen and oxygen atoms are highlighted in blue and red, respectively. Right: Diastereomeric resolution of 7 with $(S, S)$-DTTA at $25{ }^{\circ} \mathrm{C}, 400 \mathrm{rpm}$ stirring, without racemization catalysts. 

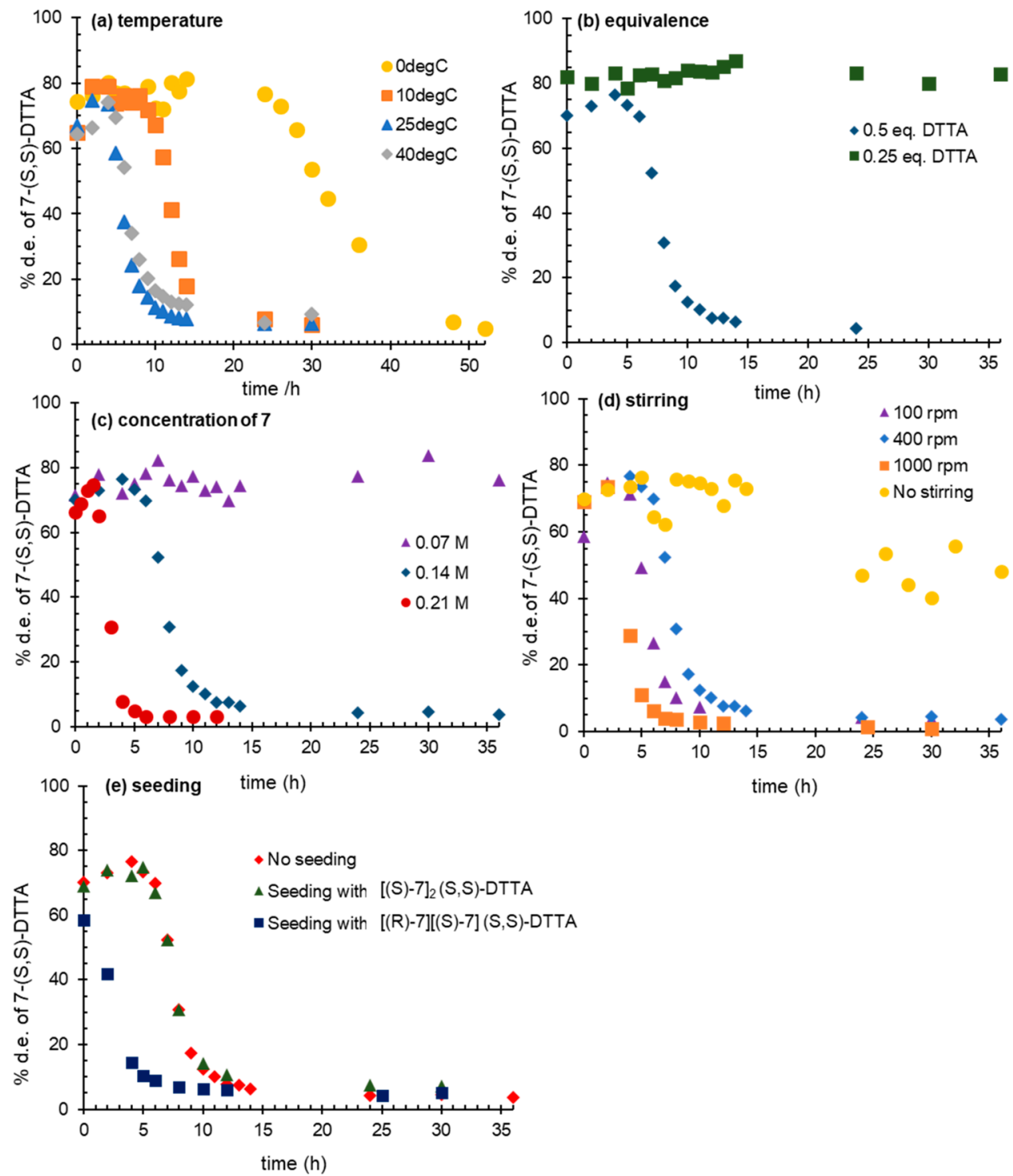

Figure 9. Effect of (a) temperature, (b) stoichiometry, (c) concentration, (d) stirring rate, and (e) seeding on the d.e. of initially formed $[(S)-7]_{2-}$ $(S, S)$-DTTA with time. The fall in d.e. in each case is due to thermodynamic switching to a meso-like $[(S)-7][(R)-7]-(S, S)$-DTTA solid form.

observed; however, its yield decreased as the solution concentration of 9 increased, concurrent with its racemization. The reaction was run over $242 \mathrm{~h}$, with a final yield of $17 \%$ solid with $77 \%$ d.e., $S=0.26$, worse than that in batch. The apparent change in diastereomer solubility was shown not to be epimerization of $(S, S)$-DTTA, so a hypothesis that the less soluble $(S)-9-(S, S)$-DTTA crystallizes more slowly than dissolution of the more soluble $(R)-9-(S, S)$-DTTA diastereomer was tested. Both diastereomers are less soluble in isopropanol:iso-propyl acetate (3:7); however, running the $\mathrm{R}^{3}$ process showed no improvement in either the yield or d.e. of (S)-9-( $S, S)$-DTTA; instead, all of the crystals dissolved after 15 recycles. The cause of this is not clear, but an explanation might be the iminium-enamine intermediates, that occur during racemization, inhibit crystal nucleation/growth.

\section{CONCLUSIONS}

An immobilized iodo-iridium racemization catalyst has been prepared, characterized, and used in fixed-bed continuous flow. Though its activity is around 10 times lower than its homogeneous counterpart. When used in the fixed bed at
5-10 mol \%, the racemization rate gives suitable residence times; extended use gives effective loadings that depend on the duration of the experiment (tested up to $190 \mathrm{~h}$ continuous or 10 days intermittent flow). A variety of benzylic and cyclic secondary amines have been racemized with steady-state TOFs of $2.8-252 \mathrm{~h}^{-1}$ and a tertiary amine with $2.2 \mathrm{~h}^{-1}$ in solvents that are compatible with diastereomeric crystallization. Primary amines are unsuitable for the iodo-iridium catalyst as the intermediate imine is too reactive, forming ammonia that rapidly inactivates the catalyst. In this case, the addition of isopropanol hydrogen donor failed to suppress the side-reactions. It was found that racemization of $\mathrm{N}$-methylamines causes slow catalyst deactivation as a result of the hydrolysis of the imine intermediate and subsequent release of methylamine. ${ }^{38}$ Reducing the moisture content of the system and using isopropanol as a cosolvent and hydrogen donor suppressed this side-reaction. A partial catalyst reactivation was identified using hydroiodic acid, but a lengthy washing procedure precluded its further use.

The continuous racemization was applied in a new resolution-racemization-recycle $\left(\mathrm{R}^{3}\right)$ process in which tubing 
connected the racemization catalyst to the crystallizer, allowing continuous recirculation of the mother liquors. This allowed both reactions to be operated separately at different temperatures. The resolvability of amines 8-11 (S)-MA salts was improved using the $R_{3}$ process by $1.6-11$ times over batch. The exception was amine 7 , but its resolution was more successful using the diacid $(S, S)$-DTTA. In this case, a surprising effect was observed, when, instead of harvesting the solid soon after it was formed, it was left until the next day, the d.e. dropped from $>70 \%$ to almost zero. Investigation of the crystal structures showed a change in molecular structure, producing a more stable meso-like or "neutral" form in which the chiralities of both $N$-methylphenethylammonium molecules were $(R)$ and $(S)$ rather than being both $(S)$ as they were at the start. ${ }^{42}$ The racemization of DTTA was eliminated. The switch in structure appeared to be stochastic and affected by temperature, mixing, concentration, stoichiometry, and seeding. These parameters are those that affect secondary nucleation rates, like those seen in CIAT and in polymorph switches. By slow addition of the diacid with (fast) racemization of $(R)-7$, the switch to the meso-like form can be avoided, giving a 44-fold improvement in resolvability over the control diastereomeric crystallization, achieving $78 \%$ yield and $86 \%$ d.e. The difficulty this exposes is that a good or bad resolution with a diacid depends on when the sample is taken; a low d.e. might be dismissed as a failed set of conditions, whereas a sample taken with high d.e. might cause problems later on when the crystallization is held. A different explanation is needed for the failure to resolve $N, N$-dimethylphenethylamine 9 which forms a 1:1 salt with $(S, S)$-DTTA. In this case, racemization and recirculation cause dissolution of the solid which might be accumulation of impurities that slow crystal nucleation and growth but not dissolution. Further work is required to confirm this.

As with other CIDT processes, the increased optical purity is likely to occur through dissolution of the more soluble diastereomer, and crystallization of the less soluble one, and is driven by the difference in concentration between the raffinate and racemized feed. As material of low d.e. is returned to the crystallizer, it is enriched in the less soluble diastereomer and causes its supersaturation, while the dynamic equilibrium is maintained by dissolution of the more soluble one. Since the dynamic system in the $\mathrm{R}^{3}$ process in most cases allows formation of the most thermodynamically stable diastereomer, the yield and d.e. are both determined by the diastereomer solubilities and the resolution rates by the racemization, crystal growth, and dissolution. More work is required to quantify and model these. Prior determination of these parameters in different solvents might overcome the usual need for careful solvent, temperature, and chiral acid screening to find the optimal resolution conditions.

The $\mathrm{R}^{3}$ process provides a simple, reproducible, low cost, and low waste method of producing chiral amines. If the catalyst activity could be increased further, the process might be amenable for use in chiral amine manufacture and studies on this are in progress. Continuous flow racemization might also be applied to CIAT, enzyme DKR, and chiral chromatographic resolution processes. Potential applications are in the end-of-pipe resolution processes to recover waste amine, for example, in chromatographic, enzymatic, or crystal resolution processes.

\section{EXPERIMENTAL SECTION}

General Information. Unless otherwise stated, all chemicals were obtained from Sigma-Aldrich, Fisher Scientific, Alfa Aesar, or Fluorochem and were used without further purification. All solvents used were HPLC grade. The syringe pumps used were Harvard Apparatus Model 11 from Scientific Support. Column chromatographic purifications were performed using Biotage (Isolera Spektra One, silica column $=$ RediSep $R_{f}$ ). Nuclear magnetic resonance (NMR) spectra were recorded on a Bruker 500 UltraShield Spectrometer operating at $500 \mathrm{MHz}\left({ }^{1} \mathrm{H} \mathrm{NMR}\right)$ and $126 \mathrm{MHz}$ $\left({ }^{13} \mathrm{C}\right.$ NMR). Liquid chromatography-mass spectrometry (LCMS) was performed on an Agilent Technologies 1200 Series LC system with a C18 column (Phenomenex Luna 5u C18(2), $50 \mathrm{~mm} \times 2 \mathrm{~mm}$ $\times 5 \mu \mathrm{m})$ eluted with an acetonitrile/water gradient (15-95\% acetonitrile, $0.1 \%$ formic acid over $3 \mathrm{~min}$ ) and a Bruker Daltonics HCTUltra system equipped with an ion trap MS detector, or a Thermo Ultimate 3000 UHPLC system with a C18 column (Phenomenex Kinetex, $50 \mathrm{~mm} \times 2.1 \mathrm{~mm} \times 2.6 \mu \mathrm{m}$ ) eluted with an acetonitrile/water gradient (2-95\% acetonitrile, $0.1 \%$ formic acid over $1 \mathrm{~min}$ ) and a Bruker Amazon Speed ion trap mass spectrometer. High resolution mass spectrometry (HRMS) was performed on a Bruker Maxis Impact Electron Spray Ionization (ESI) spectrometer with a qTOF mass analyzer. For clarity in the assignment of MS peaks of the amine salts, the cationic and anionic fragments were assigned as $\mathbf{X}$ and $\mathbf{Y}$, respectively. Melting points were recorded using a Stuart Scientific SMP3 melting point apparatus. FT-IR was recorded using a Bruker Platinum-ATR spectrometer. Optical rotations $\left([\alpha]_{\mathrm{D}}\right)$ were measured using a Polartronic H532 at $589 \mathrm{~nm}$. Achiral and chiral gas chromatography (GC) were used to determine the conversion and enantiomeric excess (ee) of the substrates $(7,8,10,11$, and 12), respectively. They were performed using a HP6890 series GC system, Agilent Technologies 7683 series injector, and HP7683 series autosampler. The e.e. of $\mathbf{1 0}$ and diastereomeric excess (d.e.) of mandelate salts were analyzed by chiral high performance liquid chromatography (HPLC) using an Agilent Technologies 1290 Infinity system, while the e.e. of (S)-MA was analyzed by chiral HPLC using an Agilent 1100 Series system. The calculations of resolvability, yield, residence time, and total process time are given in Supporting Information section 1 . The supported SCRAM catalyst 1 was prepared as previously reported. ${ }^{32}$

Optical rotations $\left([\alpha]_{\mathrm{D}}\right)$ were measured using a Polartronic H532 at $589 \mathrm{~nm}$ and were calculated as

$$
[\alpha]_{\mathrm{D}}^{T}=\frac{\text { rotation } \times 100}{c \times l}
$$

where $T=$ temperature; $c=$ concentration of sample in $\mathrm{g} / 100 \mathrm{~mL}$; and $l=$ path length, which is the length of the cell in $\mathrm{dm}$ (the cell used was $1 \mathrm{dm}$ ).

Achiral and chiral gas chromatography (GC) were used to determine the conversion and enantiomeric excess (ee) of the substrates $(7,8$, and 11$)$, respectively. They were performed using a HP6890 series GC system, Agilent Technologies 7683 series injector, and HP7683 series autosampler. The ee of $\mathbf{1 0}$ and diastereomeric excess (de) of the MA salts of $\mathbf{1 0}$ were analyzed by chiral high performance liquid chromatography (HPLC) using an Agilent Technologies 1290 Infinity system, while the ee of MA was analyzed by chiral HPLC using an Agilent 1100 Series system.

In all resolution and $\mathrm{R}^{3}$ processes, the resolvability of the system $S$ was calculated as

$$
S=2 \times \text { yield } \times \text { d.e. }
$$

where yield is a function of the quantity of amines in the system irrespective of the amount of chiral acids charged, assuming the stoichiometry of the amine and acid in the salts remain constant under the conditions employed, and was calculated as

$$
\text { yield }=\frac{m_{\text {crystals }}}{\left(\frac{n_{\text {amine }}}{r} \times \mathrm{M}_{\text {salt }}\right)} \times 100 \%
$$


where $m_{\text {crystals }}$ is the mass of crystals obtained from the resolution; $n_{\text {amine }}$ is the number of moles of amine in the system; $r$ is the ratio of amine:acid in the salt; and $M_{\text {salt }}$ is the molar mass of the salt formed.

For all flow processes, residence time was calculated as

$$
T_{\mathrm{r}}=\frac{\mathrm{RV}}{\text { flow rate }}
$$

where $\mathrm{RV}$ is the volume of the reactor.

The total process time of the $\mathrm{R}^{3}$ process was calculated as the product of residence time $\tau_{\mathrm{r}}$ and number of cycles (eq S1.5).

$$
\text { total process time }=T_{\mathrm{r}} \times \text { number of cycles }
$$

Stock solutions of known concentrations of 7, 8, 10, 11, 6,7dimethoxy-1-methyl-3,4-dihydroisoquinoline, acetophenone, and the internal standards were prepared (Table S2.1). For each calibration sample, a known volume of the stock solution and internal standard $(50 \mathrm{mM}, 20 \mu \mathrm{L}$ ) were diluted into ethyl acetate to make up $1 \mathrm{~mL}$. The samples were analyzed by achiral GC. The calibration curves were produced by plotting the peak area ratio of the compounds to the internal standard against the concentration of the compound (Figures S2.1-S2.7).

General Procedure for Continuous Flow Racemization. All of the racemic and optically active amines used in the study are known, and methods for their synthesis, along with characterization data, are described below. Fresh catalyst 1 (ICP 6.3\%, 0.32 g, 0.11 mmol of Ir) was used to racemize each optically active amine using the equipment shown in Supporting Information section 8. The catalyst was mixed with sand and loaded into an empty stainless HPLC column $(4 \mathrm{~mL})$. The column was placed inside an aluminum block which was connected to an electrical heater and equilibrated with the selected solvent. The liquid volume was determined by mass difference. A solution of amine $(2.1 \mathrm{mmol})$ in solvent $(20 \mathrm{~mL})$ at room temperature was pumped from a syringe through the heated column at a specific flow rate. The eluent was collected from the second reactor volume onward. When all of the reaction mixture was pumped, the column was washed with the reaction solvent or isopropyl alcohol while cooling to room temperature. Each collected fraction was sampled and analyzed to determine its e.e. Detail procedures of sampling and analysis were shown in Supporting Information section 7 . The e.e. at steady state was calculated as the average from reactor volumes $2-5$.

Synthesis of Catalysts. Catalysts and intermediates 1-5 were prepared using published procedures. ${ }^{33}$

Synthesis of Amines. Racemic $\alpha$-methylbenzylamine 6, (S)- $\alpha$ methylbenzylamine (S)-6, racemic $N, N$-dimethyl- $\alpha$-methylbenzylamine 9, (S)-N,N-dimethyl- $\alpha$-methylbenzylamine (S)-9, (R)-N,Ndimethyl- $\alpha$-methylbenzylamine $(R)-9$, racemic 2-methylpiperidine 11, and $(S)$-2-Methylpiperidine $(S)$-11 were bought from Sigma-Aldrich Ltd. (1S,4S)-N-Methyl-4-(3,4-dichloro)phenyl-1-amino-1,2,3,4-tetrahydronaphthalene $\mathbf{1 2}$ was received as a gift from S.Amit and Co. India Ltd.

\section{$N$-Methyl- $\alpha$-methylbenzylimine.}

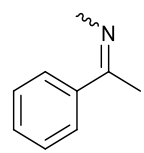

Acetophenone $(10 \mathrm{~g}, 83.2 \mathrm{mmol})$ and degassed ethanol $(40 \mathrm{~mL})$ were added to a round-bottom flask containing molecular sieves ( $3 \AA$, $16 \mathrm{~g}$ ) which was purged with nitrogen, followed by the addition of methylamine solution in ethanol (33\% wt, $22 \mathrm{~mL})$. The mixture was stirred at room temperature for $48 \mathrm{~h}$. The reaction was then filtered through Celite and was washed with dichloromethane. The solvent was removed in vacuo to give a yellow oil $(12.5 \mathrm{~g})$ which contained about $10 \%$ acetophenone (by ${ }^{1} \mathrm{H} \mathrm{NMR}$ ). The $E / Z$ isomeric ratio of crude imine was not determined and was used directly in the next step without further purification. ${ }^{1} \mathrm{H}$ NMR $\left(500 \mathrm{MHz}, \mathrm{CDCl}_{3}\right) \delta 7.74$ (dd, $J=6.5$ and $3.0 \mathrm{~Hz}, 2 \mathrm{H}), 7.39-7.34(\mathrm{~m}, 3 \mathrm{H}), 3.34(\mathrm{~s}, 3 \mathrm{H}), 2.22(\mathrm{~s}$, $3 \mathrm{H}) ;{ }^{13} \mathrm{C}\left\{{ }^{1} \mathrm{H}\right\} \mathrm{NMR}\left(126 \mathrm{MHz}, \mathrm{CDCl}_{3}\right) \delta 167.1,141.2,129.4,128.2$,
126.4, 39.5, 15.1. The spectral data correspond to those reported in the literature. ${ }^{43} \nu_{\max } / \mathrm{cm}^{-1}: 1634,1578,1493,1445,1396,1365,1284$. Racemic N-Methyl- $\alpha$-methylbenzylamine, 7.<smiles>CNC(C)c1ccccc1</smiles>

$N$-Methyl- $\alpha$-methylbenzylimine $(12.4 \mathrm{~g}, 93.1 \mathrm{mmol})$ was dissolved into methanol $(200 \mathrm{~mL})$. The mixture was cooled to $<0{ }^{\circ} \mathrm{C}$. Sodium borohydride ( $18.3 \mathrm{~g}, 484.5 \mathrm{mmol})$ was added slowly in portions over $2 \mathrm{~h}$ to maintain the temperature at $<10{ }^{\circ} \mathrm{C}$. After the addition was complete, the reaction mixture was warmed to room temperature. After $24 \mathrm{~h}$ of stirring, the reaction was cooled to $0-5{ }^{\circ} \mathrm{C}$ and was acidified by aqueous hydrochloric acid $(2 \mathrm{M}, 250 \mathrm{~mL})$. The mixture was concentrated in vacuo to give a white solid which was basified by aqueous sodium hydroxide $(3 \mathrm{M}, 200 \mathrm{~mL})$. Dichloromethane (100 $\mathrm{mL}$ ) was added, and the mixture was separated. The aqueous layer was further extracted with dichloromethane $(2 \times 100 \mathrm{~mL})$. The combined organic layer was dried by anhydrous $\mathrm{MgSO}_{4}$ and filtered, and the solvent was removed in vacuo to give a yellow oil $(9.3 \mathrm{~g})$. The crude product was purified by column chromatography using Biotage (ethyl acetate/triethylamine gradient, 95-96.5\% ethyl acetate); TLC: silica plate, ethyl acetate/triethylamine 95:5, visualization by UV (254 $\mathrm{nm} ; R_{f}$ of product $\left.=0.33\right)$ to yield $\mathrm{rac}-7$ as a pale yellow oil $(7.9 \mathrm{~g}$, overall yield from acetophenone $=70 \%) .{ }^{1} \mathrm{H}$ NMR $(500 \mathrm{MHz}$, $\left.\mathrm{CDCl}_{3}\right) \delta 7.36-7.26(\mathrm{~m}, 4 \mathrm{H}), 7.29-7.24(\mathrm{~m}, 1 \mathrm{H}), 3.64(\mathrm{q}, J=6.5$ $\mathrm{Hz}, 1 \mathrm{H}), 2.31$ (s, $3 \mathrm{H}), 1.45$ (br s, $1 \mathrm{H}), 1.35(\mathrm{~d}, J=6.5 \mathrm{~Hz}, 3 \mathrm{H})$; ${ }^{13} \mathrm{C}\left\{{ }^{1} \mathrm{H}\right\} \mathrm{NMR}\left(126 \mathrm{MHz}, \mathrm{CDCl}_{3}\right) \delta 145.4,128.4,126.9,126.6,60.3$, 34.5, 23.9. The spectral data correspond to those reported in the literature. ${ }^{43} \nu_{\max } / \mathrm{cm}^{-1}: 3284,3025,2787,1603,1493,1475,1449$, 1281, 1222. HRMS (ESI) $m / z:[\mathrm{M}+\mathrm{H}]^{+}$Calcd for $\mathrm{C}_{9} \mathrm{H}_{14} \mathrm{~N}^{+}$ 136.1126; Found 136.47 by LCMS, +ESI-MS $[\mathrm{M}+\mathrm{H}]^{+}\left\{\right.$lit. $^{43}$ HRMS (ESI) $\left.[\mathrm{M}+\mathrm{H}]^{+}: 136.1120\right\}$.

Racemic N-Isopropyl- $\alpha$-methylbenzylamine, 8.<smiles>C[C](NC(C)C)c1ccccc1</smiles>

Acetone $(250 \mathrm{~mL})$ was added to racemic 1-phenylethylamine $(10.0 \mathrm{~g}$, $82.5 \mathrm{mmol}$ ), and the mixture was heated to reflux using a heating mantle. After $24 \mathrm{~h}$, the reaction was cooled to room temperature and the solvent was removed in vacuo to give a yellow oil. Methanol (200 $\mathrm{mL}$ ) was added, and the solution was cooled on ice. Sodium borohydride $(5.6 \mathrm{~g}, 148.0 \mathrm{mmol})$ was added, and the mixture was stirred on ice for $1.5 \mathrm{~h}$ and for a further $2.5 \mathrm{~h}$ at room temperature. The mixture was acidified by aqueous hydrochloric acid $(2 \mathrm{M})$, and the solvent was removed in vacuo to give a white solid. Water and dichloromethane were added, and the mixture was basified with aqueous sodium hydroxide $(1 \mathrm{M})$. The layers were separated. The organic layer was washed with brine and dried with anhydrous $\mathrm{MgSO}_{4}$, and the solvent was removed in vacuo to give a yellow oil (8.5 $\mathrm{g}$ ). The crude product was purified by column chromatography using Biotage (ethyl acetate/triethylamine gradient, 96.3-98.5\% ethyl acetate); TLC: silica plate, ethyl acetate/triethylamine 95:5, visualization by UV $\left(254 \mathrm{~nm} ; R_{f}\right.$ of product $\left.=0.49\right)$ to yield a pale yellow oil $(7.4 \mathrm{~g}, 55 \%) .{ }^{1} \mathrm{H} \mathrm{NMR}\left(500 \mathrm{MHz}, \mathrm{CDCl}_{3}\right) \delta 7.34-7.30(\mathrm{~m}, 4 \mathrm{H})$, $7.22(\mathrm{tt}, J=1.8,7 \mathrm{~Hz}, 1 \mathrm{H}), 3.88(\mathrm{q}, J=6.5 \mathrm{~Hz}, 1 \mathrm{H}), 2.62$ (hept, $J=$ $6.2 \mathrm{~Hz}, 1 \mathrm{H}), 1.33(\mathrm{~d}, J=6.5 \mathrm{~Hz}, 3 \mathrm{H}), 1.02(\mathrm{~d}, J=6.2 \mathrm{~Hz}, 3 \mathrm{H}), 0.99$ $(\mathrm{d}, J=6.2 \mathrm{~Hz}, 3 \mathrm{H}) ;{ }^{13} \mathrm{C}\left\{{ }^{1} \mathrm{H}\right\}$ NMR $\left(126 \mathrm{MHz}, \mathrm{CDCl}_{3}\right) \delta 146.2$, $128.4,126.7,126.5,55.1,45.5,24.9,24.1,22.2$. The spectral data correspond to those reported in the literature. ${ }^{44} \nu_{\max } / \mathrm{cm}^{-1}: 2960$, 1602, 1492, 1465, 1451, 1367, 1336. HRMS (ESI) $\mathrm{m} / z:[\mathrm{M}+\mathrm{H}]^{+}$ Calcd for $\mathrm{C}_{11} \mathrm{H}_{18} \mathrm{~N}^{+}[\mathrm{M}+\mathrm{H}]^{+}$: 164.1439; Found 164.41 by LCMS, + ESI-MS $[\mathrm{M}+\mathrm{H}]^{+}\left\{\right.$lit. $^{44}$ HRMS (ESI) $\left.[\mathrm{M}+\mathrm{H}]^{+}: 164.1434\right\}$. 
(R)-N-Isopropyl- $\alpha$-methylbenzylamine, (R)-8.

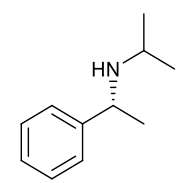

The same procedures as the synthesis of rac-8 were applied to synthesize $(R)-8$ using $(R)-1$-phenylethylamine $(2 \mathrm{~g}, 16.5 \mathrm{mmol})$. Yield $=1.8 \mathrm{~g}(68 \%)$; ee $=100 \%$ (by chiral GC after derivatization with trifluoroacetic anhydride). $[\alpha]_{\mathrm{D}}^{23}=+56.1^{\circ}$ ( $c 0.52$, chloroform $)$; the ${ }^{1} \mathrm{H}$ and ${ }^{13} \mathrm{C}$ NMR, IR, and MS data correspond to those reported for the racemate.

(S)-N-Isopropyl- $\alpha$-methylbenzylamine, (S)-8.<smiles>CC(C)NC(C)c1ccccc1</smiles>

The same procedures as the synthesis of $\mathrm{rac}-\mathbf{8}$ were applied to synthesize $(S)-8$ using $(S)$-1-phenylethylamine $(1 \mathrm{~g}, 8.3 \mathrm{mmol})$. Yield $=0.64 \mathrm{~g}(48 \%)$; ee $=98 \%$ (by chiral GC after derivatization with trifluoroacetic anhydride). $[\alpha]_{\mathrm{D}}^{23}=-61.9^{\circ}$ (c 0.40, chloroform); the ${ }^{1} \mathrm{H}$ and ${ }^{13} \mathrm{C}$ NMR, IR, and MS data correspond to those reported for the racemate.

$N$-(3,4-Dimethoxyphenethyl)acetamide. ${ }^{45}$<smiles>COc1ccc(CCNC(C)=O)cc1OC</smiles>

3,4-Dimethoxyphenethylamine (97\%, $9.9 \mathrm{~g}, 53.1 \mathrm{mmol})$ was charged to a mixture of dichloromethane $(50 \mathrm{~mL})$ and triethylamine $(12 \mathrm{~mL}$, $86.3 \mathrm{mmol}$ ), and the mixture was cooled to $0{ }^{\circ} \mathrm{C}$. With stirring, acetyl chloride $(5 \mathrm{~mL}, 70.3 \mathrm{mmol})$ was charged dropwise to the reaction mixture over $0.5 \mathrm{~h}$. The $\mathrm{pH}$ was checked to ensure the reaction mixture stayed basic. The reaction mixture was warmed to room temperature and stirred overnight. The content was then poured into ice-cold water and was acidified by aqueous hydrochloric acid (1 M). The organic and aqueous layers were separated, and the aqueous layer was further extracted with dichloromethane $(3 \times 50 \mathrm{~mL})$. The combined organic layer was washed with water $(100 \mathrm{~mL})$, dried by anhydrous $\mathrm{MgSO}_{4}$, and filtered. The solvent was removed in vacuo to yield a pale yellow solid $(12.1 \mathrm{~g})$. The product was recrystallized in hexane/ethyl acetate 1:1 to yield the acetamide product as off-white crystals $(9.2 \mathrm{~g}, 78 \%)$. Mp $98-100{ }^{\circ} \mathrm{C}\left\{\right.$ lit. $\left.^{45} 100-101{ }^{\circ} \mathrm{C}\right\} ;{ }^{1} \mathrm{H}$ NMR $\left(500 \mathrm{MHz}, \mathrm{CDCl}_{3}\right) \delta 6.82(\mathrm{~d}, J=8.0 \mathrm{~Hz}, 1 \mathrm{H}), 6.74-6.71(\mathrm{~m}, 2 \mathrm{H})$, $5.43(\mathrm{br} \mathrm{s}, 1 \mathrm{H}), 3.88(\mathrm{~s}, 3 \mathrm{H}), 3.87(\mathrm{~s}, 3 \mathrm{H}), 3.50(\mathrm{q}, J=7.0 \mathrm{~Hz}, 2 \mathrm{H})$, $2.76(\mathrm{t}, J=7.0 \mathrm{~Hz}, 2 \mathrm{H}), 1.95(\mathrm{~s}, 3 \mathrm{H}) ;{ }^{13} \mathrm{C}\left\{{ }^{1} \mathrm{H}\right\}$ NMR $(126 \mathrm{MHz}$, $\left.\mathrm{CDCl}_{3}\right) \delta 170.0,149.1,147.8,131.4,120.6,111.9,111.4,56.0,55.9$, 40.8, 35.2, 23.4. $\nu_{\max } / \mathrm{cm}^{-1}: 3249,3078,2992,2928,2839,1632$, $1563,1515,1471,1261,1233$. The spectral data correspond to those reported in the literature. ${ }^{45,46} \mathrm{HRMS}$ (ESI) $\mathrm{m} / z:[\mathrm{M}+\mathrm{H}]^{+}$Calcd for $\mathrm{C}_{12} \mathrm{H}_{18} \mathrm{NO}_{3}{ }^{+} 224.1287$; Found 224.0 by LCMS, +ESI-MS $[\mathrm{M}+\mathrm{H}]^{+}$ $\left\{\right.$ lit. $^{45}+$ ESI-MS $\left.[\mathrm{M}+\mathrm{H}]^{+}: 224.37\right\}$.

6,7-Dimethoxy-1-methyl-3,4-dihydroisoquinoline. ${ }^{47}$<smiles>COc1cc2c(cc1OC)C(C)=NCC2</smiles>

The acetamide from stage $1(6.0 \mathrm{~g}, 27.0 \mathrm{mmol})$ was added to toluene (30 mL, dried over $4 \AA$ molecular sieve, $1-2 \mathrm{~mm}$ beads) in a roundbottom flask fitted with an air condenser and calcium chloride drying tube. The mixture was warmed to $40{ }^{\circ} \mathrm{C}$ using a heating mantle. Phosphoryl chloride $(6 \mathrm{~mL}, 64.4 \mathrm{mmol})$ was charged dropwise into the mixture over $20 \mathrm{~min}$. When the addition was complete, the mixture was heated to reflux for $3 \mathrm{~h}$ using a heating mantle. The reaction mixture was then cooled to $0{ }^{\circ} \mathrm{C}$ for $2 \mathrm{~h}$. The mixture was decanted, and water was charged to the remaining solid at $0{ }^{\circ} \mathrm{C}$. The content was warmed to room temperature and stirred overnight. The reaction mixture was basified by aqueous sodium hydroxide $(5 \mathrm{M})$ and extracted with dichloromethane $(4 \times 50 \mathrm{~mL})$. The combined organic layer was dried over anhydrous $\mathrm{MgSO}_{4}$ and filtered, and the solvent was removed in vacuo to yield 6,7-dimethoxy-1-methyl-3,4dihydroisoquinoline as an orange solid $(5.4 \mathrm{~g}, 97 \%)$. The product was used in the next step without purification. $\mathrm{Mp}=103-105{ }^{\circ} \mathrm{C}\left\{\right.$ lit. $^{46}$ mp 108-109 $\left.{ }^{\circ} \mathrm{C}\right\} ;{ }^{1} \mathrm{H}$ NMR $\left(500 \mathrm{MHz}, \mathrm{CDCl}_{3}\right) \delta 6.99(\mathrm{~s}, 1 \mathrm{H}), 6.69$ $(\mathrm{s}, 1 \mathrm{H}), 3.92(\mathrm{~s}, 3 \mathrm{H}), 3.91(\mathrm{~s}, 3 \mathrm{H}), 3.63(\mathrm{dt}, J=7.5$ and $1.4 \mathrm{~Hz}, 2 \mathrm{H})$, $2.64(\mathrm{t}, J=7.5,2 \mathrm{H}), 2.36(\mathrm{t}, J=1.4 \mathrm{~Hz}, 3 \mathrm{H}) ;{ }^{13} \mathrm{C}\left\{{ }^{1} \mathrm{H}\right\}$ NMR $(126$ $\left.\mathrm{MHz}, \mathrm{CDCl}_{3}\right) \delta 163.1,150.4,147.0,130.7,122.0,109.8,108.6,55.8$, $55.5,46.6,25.3,22.9 . \nu_{\max } / \mathrm{cm}^{-1}: 2941,2924,2837,1625,1603,1571$, $1512,1286,1272,1211$. The spectral data correspond to those reported in the literature. ${ }^{46}$ HRMS (ESI) $m / z:[\mathrm{M}+\mathrm{H}]^{+}$Calcd for $\mathrm{C}_{12} \mathrm{H}_{16} \mathrm{NO}_{2}{ }^{+}$206.1181; Found 206.0 by LCMS, ESI-MS $[\mathrm{M}+\mathrm{H}]^{+}$ \{lit. ${ }^{46}$ HRMS $\left.\left[\mathrm{M}^{+}\right]: 205.1102\right\}$.

Racemic 6,7-Dimethoxy-1-methyl-1,2,3,4-tetrahydroisoquinoline, $10^{46}$<smiles>COc1cc2c(cc1OC)[C@H](C)NCC2</smiles>

6,7-Dimethoxy-1-methyl-3,4-dihydroisoquinoline (4.3 g, $21.0 \mathrm{mmol}$ ) was dissolved into methanol $(70 \mathrm{~mL})$ and was cooled to $0{ }^{\circ} \mathrm{C}$. Sodium borohydride $(4.0 \mathrm{~g}, 105.5 \mathrm{mmol})$ was added slowly in portions over $20 \mathrm{~min}$. The reaction mixture was stirred at room temperature overnight. The reaction mixture was acidified by aqueous hydrochloric acid $(1 \mathrm{M})$ and then concentrated in vacuo. The white solid obtained was basified with aqueous sodium hydroxide (1 M) and extracted with dichloromethane $(3 \times 100 \mathrm{~mL})$. The combined organic layer was washed with brine $(1 \times 50 \mathrm{~mL})$, dried over anhydrous $\mathrm{MgSO}_{4}$, and filtered, and the solvent was removed in vacuo to yield a light brown oil. The crude product was purified by column chromatography using Biotage (ethyl acetate/triethylamine gradient, 95-96.5\% ethyl acetate); TLC: silica plate, ethyl acetate/triethylamine $95: 5$, visualization by $\mathrm{UV}\left(254 \mathrm{~nm} ; R_{f}\right.$ of product $\left.=0.15\right)$ to yield rac-10 as a pale yellow oil. Off-white solid was formed overnight (3.7 g, 84\%). Mp = 35-38 ${ }^{\circ} \mathrm{C}\left\{\right.$ lit. $\left.{ }^{46} \mathrm{mp} 48-49^{\circ} \mathrm{C}\right\} ;{ }^{1} \mathrm{H}$ NMR (500 $\left.\mathrm{MHz}^{\mathrm{CDCl}}\right)_{3} \delta 6.63(\mathrm{~s}, 1 \mathrm{H}), 6.57(\mathrm{~s}, 1 \mathrm{H}), 4.05(\mathrm{q}, J=6.7 \mathrm{~Hz}, 1 \mathrm{H})$, $3.85(\mathrm{~s}, 3 \mathrm{H}), 3.84(\mathrm{~s}, 3 \mathrm{H}), 3.25(\mathrm{dt}, J=13.0$ and $5.2 \mathrm{~Hz}, 1 \mathrm{H}), 3.00$ (ddd, $J=13.0,8.8$, and $4.9 \mathrm{~Hz}, 1 \mathrm{H}$ ), 2.79 (ddd, $J=15.9,8.8$, and 5.2 $\mathrm{Hz}, 1 \mathrm{H}), 2.65(\mathrm{dt}, J=15.9$ and $4.9 \mathrm{~Hz}, 1 \mathrm{H}), 1.82$, $(\mathrm{br} \mathrm{s}, 1 \mathrm{H}), 1.44(\mathrm{~d}$, $J=6.7 \mathrm{~Hz}, 3 \mathrm{H}) ;{ }^{13} \mathrm{C}\left\{{ }^{1} \mathrm{H}\right\} \mathrm{NMR}\left(126 \mathrm{MHz} \mathrm{CDCl}_{3}\right) \delta 147.3,147.2$, $132.6,126.9,111.8,109.1,56.0,55.9,51.3,41.9,29.6,22.9 . \nu_{\max } /$ $\mathrm{cm}^{-1}: 3311,2931,2831,1609,1509,1462,1404,1253,1220$. The spectral data correspond to those reported in the literature. ${ }^{48}$ HRMS (ESI) $m / z:[\mathrm{M}+\mathrm{H}]^{+}$Calcd for $\mathrm{C}_{12} \mathrm{H}_{18} \mathrm{NO}_{2}{ }^{+}$208.1338; Found 208.0 by LCMS, +ESI-MS $[\mathrm{M}+\mathrm{H}]^{+}\left\{\right.$lit. $\left.^{48}{ }^{4 R M S}\left[\mathrm{M}^{+}\right]: 207.1258\right\}$. 10.

(S)-6,7-Dimethoxy-1-methyl-1,2,3,4-tetrahydroisoquinoline, (S)-<smiles>COc1cc2c(cc1OC)[C@@H](C)NCC2</smiles>

Formic acid $(7.2 \mathrm{~mL})$ was added to acetonitrile $(20 \mathrm{~mL})$ under nitrogen and stirred at $0{ }^{\circ} \mathrm{C}$. Triethylamine $(10.6 \mathrm{~mL})$ was added slowly to maintain the temperature at below $10{ }^{\circ} \mathrm{C}$. After the addition was complete, the reaction mixture was warmed to room temperature. $\mathrm{Ru}(p$-cymene $)(R, R$-TsDPEN) $(0.2 \mathrm{~g}, 0.3 \mathrm{mmol})$ was dissolved in acetonitrile $(25 \mathrm{~mL})$ and added to the formic acid-triethylamine mixture. The content was stirred for $15 \mathrm{~min}$. A solution of 6,7dimethoxy-1-methyl-3,4-dihydroisoquinoline (6.2 g, $30.3 \mathrm{mmol})$ in acetonitrile $(35 \mathrm{~mL})$ was charged to the reaction mixture and was warmed to $30{ }^{\circ} \mathrm{C}$ using a heating mantle. The reaction was stirred overnight. After the reaction was complete, the reaction mixture was cooled to room temperature and concentrated in vacuo. The residue was acidified with aqueous hydrochloric acid $(2 \mathrm{M})$ and washed with toluene $(2 \times 20 \mathrm{~mL})$. The aqueous layer was basified with aqueous sodium hydroxide $(5 \mathrm{M})$ and was extracted with dichloromethane (3 
$\times 50 \mathrm{~mL}$ ). The combined organic layer was dried with anhydrous $\mathrm{MgSO}_{4}$ and filtered, and the solvent was removed in vacuo to give a dark brown oil (ee $=100 \%$ by chiral HPLC). The crude product was purified by column chromatography using Biotage (ethyl acetate/ triethylamine gradient, 95-96.5\% ethyl acetate); TLC: silica plate, ethyl acetate/triethylamine 95:5, visualization by UV $\left(254 \mathrm{~nm}\right.$; $R_{f}$ of product $=0.15)$ to yield $(S)-10$ as a pale brown oil $(5.4 \mathrm{~g}, 88 \%)$. $[\alpha]_{\mathrm{D}}{ }^{23}=-54.4^{\circ}$ (c 1.10, ethanol) $\left\{\right.$ lit. $^{48}[\alpha]_{\mathrm{D}}{ }^{20}=-41.3^{\circ}$ (c 1.10, ethanol)\}. The spectral and MS data correspond to those reported for rac-10 and in the literature. ${ }^{48,50}$ 10.

(R)-6,7-Dimethoxy-1-methyl-1,2,3,4-tetrahydroisoquinoline, (R)-<smiles>COc1cc2c(cc1OC)[C@H](C)NCC2</smiles>

Similar procedures as $(S)$-10 were employed in the synthesis of $(R)$ 10 with $\mathrm{Ru}(p$-cymene)(S,S-TsDPEN). Toluene was used instead of dichloromethane in the extraction of product from the aqueous layer during workup. A pale brown oil $(5.7 \mathrm{~g}, 94 \%)$ was obtained with an ee of $96 \%$ (by chiral HPLC). $[\alpha]_{\mathrm{D}}^{23}=+52.3^{\circ}$ (c 1.13, ethanol) $\left\{\right.$ lit. $^{48}$ $[\alpha]_{\mathrm{D}}{ }^{20}=+59.7^{\circ}$ (c 1.10, ethanol) $\}$. The spectral and MS data correspond to those reported for rac-10.

(R)-2-Methylpiperidine, (R)-11.<smiles>CC1CCCCN1</smiles>

(R)-11-(S)-MA (0.25 g, $0.99 \mathrm{mmol})$ was dissolved into aqueous ammonia solution $(10 \%, 10 \mathrm{~mL})$ and was extracted with dichloromethane $(20 \mathrm{~mL})$. The mixture was separated, and the aqueous layer was further extracted with dichloromethane $(2 \times 10 \mathrm{~mL})$. The combined organic layer was dried with anhydrous $\mathrm{MgSO}_{4}$ and filtered, and the solvent was removed in vacuo to yield a pale yellow oil $(0.063$ g, 63\%) with an ee of $100 \%$ (by chiral GC after derivatization with acetic anhydride). $[\alpha]_{\mathrm{D}}{ }^{20}=-3.65^{\circ}$ (c 2.0, methanol) $\left\{\right.$ lit. $^{51}[\alpha]_{\mathrm{D}}{ }^{22}=$ $-8.5^{\circ}$ (c 0.5, methanol) $\} ;{ }^{1} \mathrm{H}$ NMR $\left(500 \mathrm{MHz}, \mathrm{CDCl}_{3}\right) \delta 3.09-3.01$ $(\mathrm{m}, 1 \mathrm{H}), 2.64(\mathrm{td}, J=11.8$ and $3.0 \mathrm{~Hz}, 1 \mathrm{H}), 2.61-2.55(\mathrm{~m}, 1 \mathrm{H})$, $1.80-1.72(\mathrm{~m}, 1 \mathrm{H}), 1.62-1.52(\mathrm{~m}, 3 \mathrm{H}), 1.44-1.28(\mathrm{~m}, 2 \mathrm{H}), 1.12-$ $0.99(\mathrm{~m}, 4 \mathrm{H}) ;{ }^{13} \mathrm{C}\left\{{ }^{1} \mathrm{H}\right\}$ NMR $\left(126 \mathrm{MHz}, \mathrm{CDCl}_{3}\right) \delta 52.3,47.1,34.6$, $26.1,24.3,23.0$. The spectral data correspond to those reported in the literature for $\mathrm{rac}-11 . \nu_{\max } / \mathrm{cm}^{-1}: 3270,2925,2854,2795,1441,1375$, 1325, 1306. HRMS (ESI) $m / z:[\mathrm{M}+\mathrm{H}]^{+}$Calcd for $\mathrm{C}_{6} \mathrm{H}_{14} \mathrm{~N}^{+}$ 100.1126; Found 100.58 by LCMS, +ESI-MS/MS $[\mathrm{M}+\mathrm{H}]^{+}\left\{\right.$lit. $^{52}$ LCMS $\left.[\mathrm{M}+\mathrm{H}]^{+}: 100.1\right\}$.

Synthesis of Diastereomeric Salts. (R)-N-Methyl- $\alpha$-methylbenzylammonium Di-p-toluoyl-D-tartrate, $[(R)-7]_{2}-(S, S)$-DTTA.
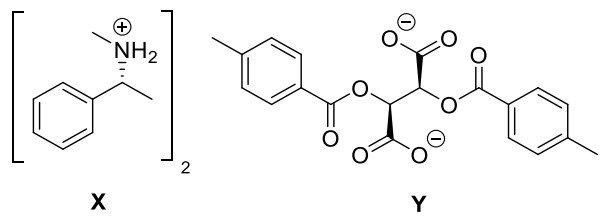

$(S, S)$-DTTA (72.5 $\mathrm{mg}, 0.19 \mathrm{mmol})$ was dissolved into ethyl acetate/ methanol 10:1 $(2.9 \mathrm{~mL})$ and was added to $(R)-7(50.7 \mathrm{mg}, 0.38$ $\mathrm{mmol}$ ). The mixture was stirred at room temperature for $1 \mathrm{~h}$ and then filtered. The solid was dried in air to obtain a white solid $(0.1 \mathrm{~g}, 80 \%)$ with $100 \%$ d.e. (by ${ }^{1} \mathrm{H}$ NMR in $d_{6}$-DMSO, $500 \mathrm{MHz}$ ). $\mathrm{Mp}=160-$ $163{ }^{\circ} \mathrm{C} ;[\alpha]_{\mathrm{D}}{ }^{20}=+102.2^{\circ}(c 0.11, \mathrm{MeOH}) ;{ }^{1} \mathrm{H} \mathrm{NMR}\left(500 \mathrm{MHz}, d_{6}-\right.$ DMSO) $\delta 7.86(\mathrm{~d}, J=8.0 \mathrm{~Hz}, 4 \mathrm{H}), 7.35(\mathrm{~m}, 14 \mathrm{H}), 5.63(\mathrm{~s}, 2 \mathrm{H}), 3.95$ $(\mathrm{q}, J=6.8 \mathrm{~Hz}, 2 \mathrm{H}), 2.37(\mathrm{~s}, 6 \mathrm{H}), 2.23(\mathrm{~s}, 6 \mathrm{H}), 1.35(\mathrm{~d}, J=6.8 \mathrm{~Hz}$, $6 \mathrm{H}) ;{ }^{13} \mathrm{C}\left\{{ }^{1} \mathrm{H}\right\}$ NMR $\left(126 \mathrm{MHz}, d_{6}\right.$-DMSO) $\delta 169.6,165.1,143.1$, 139.1, 129.3, 129.0, 128.6, 128.1, 127.8, 127.4, 74.3, 57.9, 30.7, 21.1, 20.1. $\nu_{\max } / \mathrm{cm}^{-1}: 3016,2878,1714,1633,1611,1566,1455,1371$, 1329, 1265. HRMS (ESI) $m / z:[\mathrm{M}+\mathrm{Y}]^{+}$Calcd for $\mathrm{C}_{9} \mathrm{H}_{14} \mathrm{~N}^{+}$ 136.1126; Found 136.1117. HRMS (ESI) $m / z:[M-X-Y]^{-}$ Calcd for $\mathrm{C}_{20} \mathrm{H}_{17} \mathrm{O}_{8}{ }^{-}$385.0923; Found 385.0913.
(S)-N-Methyl- $\alpha$-methylbenzylammonium Di-p-toluoyl-D-tartrate, $[(S)-7]_{2}-(S, S)-D T T A$.

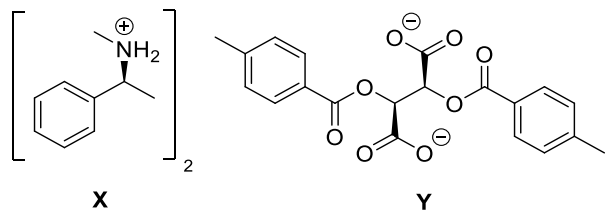

A similar procedure to that used for $[(R)-7]_{2}-(S, S)-D T T A$ was used to prepare $[(S)-7]_{2}-(S, S)$-DTTA. Using $(S)-7(50.2 \mathrm{mg}, 0.37 \mathrm{mmol})$, a white solid was obtained $(0.1 \mathrm{~g}, 80 \%)$ with $100 \%$ d.e. (by ${ }^{1} \mathrm{H}$ NMR in $d_{6}$-DMSO, $\left.500 \mathrm{MHz}\right) . \mathrm{Mp}=179-182^{\circ} \mathrm{C} ;[\alpha]_{\mathrm{D}}{ }^{20}=+69.3^{\circ}(c 0.12$, $\mathrm{MeOH}) ;{ }^{1} \mathrm{H}$ NMR (500 MHz, $d_{6}$-DMSO) $\delta 7.90(\mathrm{~d}, J=8.5 \mathrm{~Hz}, 4 \mathrm{H})$, $7.41(\mathrm{dd}, J=7.0$ and $1.5 \mathrm{~Hz}, 4 \mathrm{H}), 7.32(\mathrm{~m}, 10 \mathrm{H}), 5.66(\mathrm{~s}, 2 \mathrm{H}), 3.99$ $(\mathrm{q}, J=6.8 \mathrm{~Hz}, 2 \mathrm{H}), 2.38(\mathrm{~s}, 6 \mathrm{H}), 2.20(\mathrm{~s}, 6 \mathrm{H}), 1.38(\mathrm{~d}, J=6.8 \mathrm{~Hz}$, $6 \mathrm{H}) ;{ }^{13} \mathrm{C}\left\{{ }^{1} \mathrm{H}\right\}$ NMR $\left(126 \mathrm{MHz}, d_{6}\right.$-DMSO) $\delta 169.1,165.0,143.2$, 139.6, 129.3, 129.0, 128.6, 128.0, 127.6, 127.3, 73.6, 58.0, 31.0, 21.1, 20.5. $\nu_{\max } / \mathrm{cm}^{-1}: 3017,2870,1712,1637,1612,1594,1455,1371$, 1337, 1268. HRMS (ESI) $m / z:[\mathrm{M}+\mathrm{Y}]^{+}$Calcd for $\mathrm{C}_{9} \mathrm{H}_{14} \mathrm{~N}^{+}$ 136.1126; Found 136.1118; HRMS (ESI) $m / z$ : $[\mathrm{M}-2 \mathrm{X}+\mathrm{H}]^{-}$ Calcd for $\mathrm{C}_{20} \mathrm{H}_{17} \mathrm{O}_{8}{ }^{-}$385.0923; Found 385.0919.

(R)-N-Methyl- $\alpha$-methylbenzylammonium-(S)-mandelate, (R)-7(S)-MA.

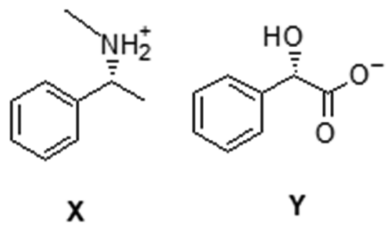

(S)-MA (0.11 g, $0.74 \mathrm{mmol})$ was dissolved into ethyl isobutyrate (2 $\mathrm{mL})$, and the solution was added to $(R)-7(0.10 \mathrm{~g}, 0.74 \mathrm{mmol})$. The slurry was heated to reflux until all solid dissolved. The mixture was cooled to room temperature with reduced stirring and was filtered to give a white solid which was dried in air overnight $(0.17 \mathrm{~g}, 82 \%)$ with d.e. $=100 \%\left(\right.$ by $\left.{ }^{1} \mathrm{H} \mathrm{NMR} \mathrm{in} \mathrm{CDCl}_{3}, 500 \mathrm{MHz}\right) . \mathrm{Mp}=109-111^{\circ} \mathrm{C}$; $[\alpha]_{\mathrm{D}}{ }^{23}=+62.3^{\circ}(c 0.49, \mathrm{MeOH}) ;{ }^{1} \mathrm{H}$ NMR $\left(500 \mathrm{MHz}, \mathrm{CDCl}_{3}\right) \delta$ $7.48(\mathrm{~d}, J=7.5 \mathrm{~Hz}, 2 \mathrm{H}), 7.32(\mathrm{~m}, 5 \mathrm{H}), 7.24(\mathrm{~m}, 3 \mathrm{H}), 4.91(\mathrm{~s}, 1 \mathrm{H})$, $3.68(\mathrm{q}, J=6.9 \mathrm{~Hz}, 1 \mathrm{H}), 1.99(\mathrm{~s}, 3 \mathrm{H}), 1.46(\mathrm{~d}, J=6.9 \mathrm{~Hz}, 3 \mathrm{H})$; ${ }^{13} \mathrm{C}\left\{{ }^{1} \mathrm{H}\right\}$ NMR $\left(126 \mathrm{MHz}, \mathrm{CDCl}_{3}\right) \delta 178.5,142.6,136.3,129.2$, $129.1,128.1,127.6,127.3,126.8,74.6,59.1,30.2,19.5 . \nu_{\max } / \mathrm{cm}^{-1}$ : $3029,2698,2460,1622,1556,1509,1491,1453,1363,1330,1302$, 1273. HRMS (ESI) $m / z:[\mathrm{M}-\mathrm{Y}]^{+}$Calcd for $\mathrm{C}_{9} \mathrm{H}_{14} \mathrm{~N}^{+} 136.1126$; Found 136.1118. HRMS (ESI) $\mathrm{m} / z$ : $[\mathrm{M}-\mathbf{X}]^{-}$Calcd for $\mathrm{C}_{8} \mathrm{H}_{7} \mathrm{O}_{3}$ 151.0395; Found 151.0397.

(S)-N-Methyl- $\alpha$-methylbenzylammonium-(S)-mandelate, (S)-7(S)-MA.

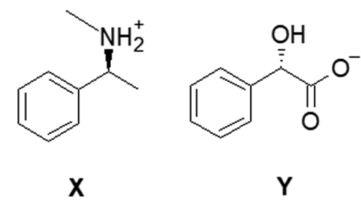

(S)-MA (0.11 g, $0.74 \mathrm{mmol})$ was dissolved into ethyl isobutyrate (1 $\mathrm{mL})$, and the solution was added to $(S)-7(0.10 \mathrm{~g}, 0.74 \mathrm{mmol})$. The mixture was stirred overnight at room temperature for solid to precipitate, which was then heated to reflux. After all solid dissolved, the mixture was cooled to room temperature with reduced stirring overnight. The slurry was filtered, and the solid collected was dried in air overnight $(0.14 \mathrm{~g}, 67 \%)$ with d.e. $=100 \%$ (by ${ }^{1} \mathrm{H} \mathrm{NMR} \mathrm{in} \mathrm{CDCl}_{3}$, $500 \mathrm{MHz}) . \mathrm{Mp}=93-94{ }^{\circ} \mathrm{C} ;[\alpha]_{\mathrm{D}}{ }^{23}=+37.5^{\circ}($ c 0.50, $\mathrm{MeOH}) ;{ }^{1} \mathrm{H}$ NMR (500 MHz, $\left.\mathrm{CDCl}_{3}\right) \delta 7.44(\mathrm{~m}, 2 \mathrm{H}), 7.36(\mathrm{~m}, 3 \mathrm{H}), 7.27(\mathrm{~m}$, $5 \mathrm{H}), 4.89(\mathrm{~s}, 1 \mathrm{H}), 3.42(\mathrm{q}, J=6.8 \mathrm{~Hz}, 1 \mathrm{H}), 2.00(\mathrm{~s}, 3 \mathrm{H}), 1.37(\mathrm{~d}, J=$ $6.8 \mathrm{~Hz}, 3 \mathrm{H}) ;{ }^{13} \mathrm{C}\left\{{ }^{1} \mathrm{H}\right\}$ NMR $\left(126 \mathrm{MHz}, \mathrm{CDCl}_{3}\right) \delta 178.5,142.5$, $136.5,129.2,129.1,128.1,127.6,127.2,126.8,74.6,59.0,30.3,19.9$. $\nu_{\max } / \mathrm{cm}^{-1}: 3301,2706,2465,1623,1578,1451,1380,1359,1330$, 1314, 1279, 1220. HRMS (ESI) $\mathrm{m} / z$ : $[\mathrm{M}-\mathrm{Y}]^{+}$Calcd for $\mathrm{C}_{9} \mathrm{H}_{14} \mathrm{~N}^{+}$ 136.1126; Found 136.1114. HRMS (ESI) $m / z:[\mathrm{M}-\mathbf{X}]^{-}$Calcd for $\mathrm{C}_{8} \mathrm{H}_{7} \mathrm{O}_{3}$ 151.0395; Found 151.0398. 
(R)-N-Isopropyl-1-phenylethylammonium-(S)-mandelate, (R)-8(S)-MA.

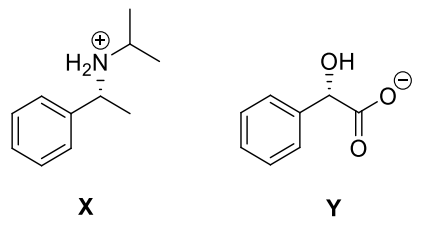

(S)-MA (0.094 g, $0.62 \mathrm{mmol})$ and $(R)-8(0.1 \mathrm{~g}, 0.62 \mathrm{mmol})$ were dissolved in isopropyl acetate $(1.5$ and $0.5 \mathrm{~mL}$, respectively). The two solutions were mixed, and more isopropyl acetate $(8 \mathrm{~mL})$ was added. The mixture was heated to reflux using a heating mantle. Isopropanol was added until all solid dissolved. The mixture was then cooled to room temperature with reduced stirring and was filtered to give a white fluffy solid $(0.14 \mathrm{~g}, 74 \%)$ with $100 \%$ d.e. (by ${ }^{1} \mathrm{H}$ NMR in $\left.\mathrm{CDCl}_{3}, 500 \mathrm{MHz}\right) . \mathrm{Mp}=169-174{ }^{\circ} \mathrm{C} ;[\alpha]_{\mathrm{D}}{ }^{23}=+61.5^{\circ}$ (c 0.39 , methanol); ${ }^{1} \mathrm{H}$ NMR $\left(500 \mathrm{MHz}, \mathrm{CDCl}_{3}\right) \delta 7.52(\mathrm{~d}, J=7.5 \mathrm{~Hz}, 2 \mathrm{H})$, $7.32(\mathrm{~m}, 7 \mathrm{H}), 7.22(\mathrm{t}, J=7.5 \mathrm{~Hz}, 1 \mathrm{H}), 4.94(\mathrm{~s}, 1 \mathrm{H}), 3.99(\mathrm{q}, J=6.7$ $\mathrm{Hz}, 1 \mathrm{H}), 2.72$ (hept, $J=6.4 \mathrm{~Hz}, 1 \mathrm{H}), 1.46(\mathrm{~d}, J=6.5 \mathrm{~Hz}, 3 \mathrm{H}), 1.12$ $(\mathrm{d}, J=6.5 \mathrm{~Hz}, 3 \mathrm{H}), 0.96(\mathrm{~d}, J=6.4 \mathrm{~Hz}, 3 \mathrm{H}) ;{ }^{13} \mathrm{C}\left\{{ }^{1} \mathrm{H}\right\}$ NMR $(126$ $\left.\mathrm{MHz} \mathrm{CDCl}_{3}\right) \delta 177.2,142.4,136.9,129.1,128.8,128.0,127.7,127.1$, $126.7,74.7,55.5,47.2,20.6,19.9,17.6 . \nu_{\max } / \mathrm{cm}^{-1}: 3040,2866,2679$, 2461, 1617, 1568, 1518, 1490, 1446, 1364, 1329, 1265, 1217. HRMS (ESI) $m / z:[\mathrm{M}+\mathrm{Y}]^{+}$Calcd for $\mathrm{C}_{11} \mathrm{H}_{18} \mathrm{~N}^{+}$164.1439; Found 164.1429; HRMS (ESI) $m / z$ : $[\mathrm{M}-\mathbf{X}]^{-}$Calcd for $\mathrm{C}_{8} \mathrm{H}_{7} \mathrm{O}_{3}{ }^{-}$ 151.0395; Found 151.0391.

(S)-N-Isopropyl-1-phenylethylammonium-(S)-mandelate, (S)-8(S)-MA.<smiles>CC(C)NC(C)c1ccccc1</smiles><smiles>O=C([O-])C(O)c1ccccc1</smiles>

(S)-MA (0.093 g, $0.61 \mathrm{mmol})$ and $(S)-8(0.1 \mathrm{~g}, 0.61 \mathrm{mmol})$ were dissolved in isopropyl acetate $(1.5$ and $0.5 \mathrm{~mL}$, respectively) at room temperature. The two solutions were mixed and the solvent evaporated in vacuo to give a thick oil which solidified upon standing (0.17 g, 90\%); $100 \%$ d.e. (by ${ }^{1} \mathrm{H}$ NMR in $\left.\mathrm{CDCl}_{3}, 500 \mathrm{MHz}\right) . \mathrm{Mp}=$ 97-102 ${ }^{\circ} \mathrm{C} ;[\alpha]_{\mathrm{D}}{ }^{23}=+36.2^{\circ}$ (c 0.51, methanol); ${ }^{1} \mathrm{H}$ NMR (500 $\left.\mathrm{MHz}_{\mathrm{CDCl}}\right) \delta 7.47(\mathrm{~d}, J=6.9 \mathrm{~Hz}, 2 \mathrm{H}), 7.40(\mathrm{~m}, 5 \mathrm{H}), 7.27(\mathrm{~m}$, $3 \mathrm{H}), 4.97(\mathrm{~s}, 1 \mathrm{H}), 3.70(\mathrm{q}, J=6.8 \mathrm{~Hz}, 1 \mathrm{H}), 2.69(\mathrm{~m}, 1 \mathrm{H}), 1.33(\mathrm{~d}, J=$ $6.5 \mathrm{~Hz}, 3 \mathrm{H}), 1.09(\mathrm{~d}, J=6.5 \mathrm{~Hz}, 3 \mathrm{H}), 0.99(\mathrm{~d}, J=6.5 \mathrm{~Hz}, 3 \mathrm{H})$; ${ }^{13} \mathrm{C}\left\{{ }^{1} \mathrm{H}\right\}$ NMR $\left(126 \mathrm{MHz}, \mathrm{CDCl}_{3}\right) \delta 177.3,141.9,136.8,129.2$, 128.9, 128.0, 127.6, 127.3, 126.7, 74.4, 55.4, 47.3, 20.7, 19.7, 17.7. $\nu_{\max } / \mathrm{cm}^{-1}: 3385,2985,2716,2514,1709,1625,1596,1454,1390$, 1357, 1276, 1214. HRMS (ESI) $m / z:[\mathrm{M}-\mathrm{Y}]^{+}$Calcd for $\mathrm{C}_{11} \mathrm{H}_{18} \mathrm{~N}^{+}$ 164.1439; Found 164.1429; HRMS (ESI) $m / z$ : $[\mathrm{M}-\mathrm{X}]^{-}$Calcd for $\mathrm{C}_{8} \mathrm{H}_{7} \mathrm{O}_{3}^{-}$151.0395; Found 151.0395.

(R)-N,N-Dimethyl- $\alpha$-methylbenzylammonium Di-p-toluoyl-Dtartrate, [(R)-9]-(S,S)-DTTA.

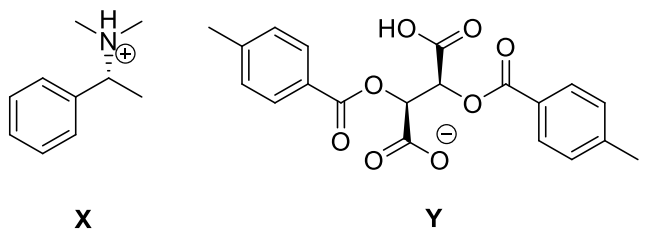

$(S, S)$-DTTA $(0.26 \mathrm{~g}, 0.67 \mathrm{mmol})$ and $(R)-9(99.7 \mathrm{mg}, 0.67 \mathrm{mmol})$ were dissolved into isopropyl acetate ( 3 and $2 \mathrm{~mL}$, respectively). The two solutions were mixed, stirred, and heated to reflux using a heating mantle. More isopropyl acetate $(9 \mathrm{~mL})$ was added until all solid dissolved. Stirring was stopped. The reaction mixture was cooled to room temperature and filtered to give a white crystalline solid $(0.24 \mathrm{~g}$, $67 \%$ ). A small amount of crystals was dissolved into aqueous sodium carbonate solution $(10 \% \mathrm{w} / \mathrm{v}, 1 \mathrm{~mL})$ and extracted with ethyl acetate
( $1 \mathrm{~mL}$ ). The organic layer was dried with anhydrous $\mathrm{MgSO}_{4}$ and filtered through a plug of Celite. A solution of (S)-MA in methanol $\left(21 \mathrm{mg} \mathrm{mL}^{-1}, 100 \mu \mathrm{L}\right)$ was added, and the mixture was sonicated and then dried in vacuo. The residue was analyzed by ${ }^{1} \mathrm{H}$ NMR $(500 \mathrm{MHz}$, $d_{6}$-DMSO) $\delta 7.83(\mathrm{~d}, J=8.0 \mathrm{~Hz}, 4 \mathrm{H}), 7.45-7.39(\mathrm{~m}, 2 \mathrm{H}), 7.39-7.34$ $(\mathrm{m}, 3 \mathrm{H}), 7.31(\mathrm{~d}, J=8.0 \mathrm{~Hz}, 4 \mathrm{H}), 5.67(\mathrm{~s}, 2 \mathrm{H}), 4.10(\mathrm{br} \mathrm{d}, J=7.3 \mathrm{~Hz}$, $1 \mathrm{H}), 2.44(\mathrm{~s}, 6 \mathrm{H}), 2.35(\mathrm{~s}, 6 \mathrm{H}), 1.45(\mathrm{~d}, J=7.3 \mathrm{~Hz}, 3 \mathrm{H}) ;{ }^{13} \mathrm{C}\left\{{ }^{1} \mathrm{H}\right\}$ NMR $\left(75 \mathrm{MHz}, d_{6}\right.$-DMSO) $\delta 168.1,164.8,143.8,136.7,129.3$, $129.3,129.1,128.8,128.7,128.5,126.7,72.0,64.4,21.2,16.8 . \nu_{\max } /$ $\mathrm{cm}^{-1}:$ 2984, 2731, 1719, 1680,1610,1456, 1406, 1388, 1338, 1265, 1252, 1232. HRMS (ESI) $m / z:[\mathrm{M}-\mathbf{Y}]^{+}$Calcd for $\mathrm{C}_{10} \mathrm{H}_{15} \mathrm{~N}^{+}$ 150.1283; Found 150.1249. HRMS (ESI) $m / z:[\mathrm{M}-\mathrm{X}]^{-}$Calcd for $\mathrm{C}_{20} \mathrm{H}_{17} \mathrm{O}_{8}^{-}$385.0923; Found 385.0828.

(S)-N,N-Dimethyl- $\alpha$-methylbenzylammonium Di-p-toluoyl-D-tartrate, [(S)-9]-(S,S)-DTTA.

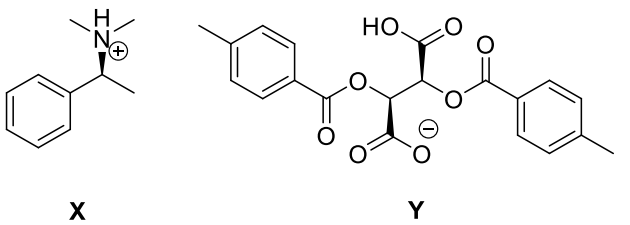

A similar procedure to that above was used to synthesize $(S)-9-(S, S)$ DTTA. After more isopropyl acetate was added to the hot solution of $(S)-9 /(S, S)$-DTTA, isopropyl alcohol $(8 \mathrm{~mL})$ was added for the complete dissolution of the precipitate. (S)-9-(S,S)-DTTA was isolated as a white crystalline solid $(0.26 \mathrm{~g}, 73 \%)$ with d.e. $=100 \%$ (determined as the ee of 9). $\mathrm{Mp}=140-141{ }^{\circ} \mathrm{C} ;[\alpha]_{\mathrm{D}}{ }^{20}=+200.2^{\circ}(\mathrm{c}$ 0.5 , methanol); ${ }^{1} \mathrm{H}$ NMR (500 MHz, $d_{6}$-DMSO) $\delta 7.84$ (d, $J=8.0$ $\mathrm{Hz}, 4 \mathrm{H}), 7.45-7.39(\mathrm{~m}, 2 \mathrm{H}), 7.35(\mathrm{t}, J=3.3 \mathrm{~Hz}, 3 \mathrm{H}), 7.31(\mathrm{~d}, J=8.0$ $\mathrm{Hz}, 4 \mathrm{H}), 5.68(\mathrm{~s}, 2 \mathrm{H}), 4.13(\mathrm{q}, J=6.7 \mathrm{~Hz}, 1 \mathrm{H}), 2.43(\mathrm{~s}, 6 \mathrm{H}), 2.36(\mathrm{~s}$, $6 \mathrm{H}), 1.47(\mathrm{~d}, J=6.7 \mathrm{~Hz}, 3 \mathrm{H}) ;{ }^{13} \mathrm{C}\left\{{ }^{1} \mathrm{H}\right\} \mathrm{NMR}\left(75 \mathrm{MHz}, d_{6}\right.$-DMSO) $\delta$ $168.0,164.8,143.8,136.8,129.3,129.2,129.1,128.8,128.6,128.5$, 126.7, 71.9, 64.3, 21.2, 16.8. $\nu_{\max } / \mathrm{cm}^{-1}: 2955,2701,1719,1681$, 1611, 1458, 1408, 1325, 1251. HRMS (ESI) $\mathrm{m} / z$ : $[\mathrm{M}-\mathrm{Y}]^{+}$Calcd for $\mathrm{C}_{10} \mathrm{H}_{15} \mathrm{~N}^{+}$150.1283; Found 150.1248. HRMS (ESI) $m / z$ : $[\mathrm{M}-\mathbf{X}]^{-}$ Calcd for $\mathrm{C}_{20} \mathrm{H}_{17} \mathrm{O}_{8}{ }^{-}$385.0923; Found 385.0818.

(R)-6,7-Dimethoxy-1-methyl-1,2,3,4-tetrahydroisoquinolinium(S)-mandelate, (R)-10-(S)-MA.<smiles>[X]C1NCCc2cc(OC)c(OC)cc21</smiles>

A solution of (S)-MA $(0.3 \mathrm{~g}, 1.9 \mathrm{mmol})$ in ethyl acetate/methanol 7:1 $(2 \mathrm{~mL})$ was added to a solution of $(R)-10(0.4 \mathrm{~g}, 1.9 \mathrm{mmol})$ in ethyl acetate/methanol 7:1 $(2 \mathrm{~mL})$. The mixture was heated to reflux using a heating mantle. More ethyl acetate/methanol 7:1 was added until all of the solids dissolved. The stirring was stopped and the heat switched off, allowing the mixture to cool to room temperature. The slurry was filtered to give an off-white crystalline solid (0.4 g, 47\%) with 100\% d.e. (by ${ }^{1} \mathrm{H}$ NMR in $\mathrm{CDCl}_{3}, 500 \mathrm{MHz}$ ). The resolution results are shown in Supporting Information Table S7.1. $\mathrm{Mp}=172-174{ }^{\circ} \mathrm{C}$; $[\alpha]_{\mathrm{D}}{ }^{23}=+66.3^{\circ}(c 1.10$, chloroform $) ;{ }^{1} \mathrm{H}$ NMR $\left(500 \mathrm{MHz}, \mathrm{CDCl}_{3}\right) \delta$ $7.31-7.23(\mathrm{~m}, 2 \mathrm{H}), 7.20-7.15(\mathrm{~m}, 3 \mathrm{H}), 6.55(\mathrm{~s}, 1 \mathrm{H}), 6.48(\mathrm{~s}, 1 \mathrm{H})$, $4.74(\mathrm{~s}, 1 \mathrm{H}), 4.17(\mathrm{q}, J=6.6 \mathrm{~Hz}, 1 \mathrm{H}), 3.87(\mathrm{~s}, 3 \mathrm{H}), 3.86(\mathrm{~s}, 3 \mathrm{H})$, $3.24-3.13(\mathrm{~m}, 1 \mathrm{H}), 2.95-2.84(\mathrm{~m}, 2 \mathrm{H}), 2.79-2.68(\mathrm{~m}, 1 \mathrm{H}), 1.41(\mathrm{~d}$, $J=6.6 \mathrm{~Hz}, 3 \mathrm{H}) ;{ }^{13} \mathrm{C}\left\{{ }^{1} \mathrm{H}\right\} \mathrm{NMR}\left(126 \mathrm{MHz}, \mathrm{CDCl}_{3}\right) \delta 178.8,148.6$, $148.3,142.1,127.9,127.0,126.4,125.7,123.6,111.3,108.7,74.4$, 56.1, 56.0, 50.3, 38.9, 25.3, 19.6. $\nu_{\max } / \mathrm{cm}^{-1}: 3188,3061,2832,2757$, 2656, 2573, 2525, 2493, 1582, 1518, 1366, 1244, 1211. HRMS (ESI) $m / z:[\mathrm{M}-\mathrm{Y}]^{+}$Calcd for $\mathrm{C}_{12} \mathrm{H}_{18} \mathrm{NO}_{2}{ }^{+}$208.1337; Found 208.53 by LCMS, ESI-MS/MS. HRMS (ESI) $m / z:[\mathrm{M}-\mathbf{X}]^{-}$Calcd for $\mathrm{C}_{8} \mathrm{H}_{7} \mathrm{O}_{3}{ }^{-}$151.0395; Found 150.87 by LCMS, ESI-MS/MS. 
(S)-6,7-Dimethoxy-1-methyl-1,2,3,4-tetrahydroisoquinolinium(S)-mandelate, (S)-10-(S)-MA.<smiles>[X]c1cc2c(cc1OC)C(C)[NH2+]CC2</smiles>

A similar procedure to that above was used to synthesize $(S)$-10-(S)MA. Ethyl acetate/methanol 15:1 was used as the solvent mixture. (S)-10-(S)-MA was isolated as an off-white crystalline solid (0.2 g, $32 \%$ ) with $100 \%$ d.e. (by ${ }^{1} \mathrm{H} \mathrm{NMR}$ in $\mathrm{CDCl}_{3}, 500 \mathrm{MHz}$ ). $\mathrm{Mp}=163-$ $166{ }^{\circ} \mathrm{C} ;[\alpha]_{\mathrm{D}}{ }^{23}=+39.6^{\circ}$ (c 1.10, chloroform); ${ }^{1} \mathrm{H}$ NMR $(500 \mathrm{MHz}$, $\left.\mathrm{CDCl}_{3}\right) \delta 7.31(\mathrm{~d}, J=7.0 \mathrm{~Hz}, 2 \mathrm{H}), 7.24-7.14(\mathrm{~m}, 3 \mathrm{H}), 6.53(\mathrm{~s}, 1 \mathrm{H})$, $6.47(\mathrm{~s}, 1 \mathrm{H}), 4.77(\mathrm{~s}, 1 \mathrm{H}), 3.98(\mathrm{q}, J=6.6 \mathrm{~Hz}, 1 \mathrm{H}), 3.87(\mathrm{~s}, 3 \mathrm{H}), 3.86$ $(\mathrm{s}, 3 \mathrm{H}), 3.16(\mathrm{dt}, J=12.5$ and $5.5 \mathrm{~Hz}, 1 \mathrm{H}), 2.98$ (ddd, $J=12.5,8.0$ and $5.5 \mathrm{~Hz}, 1 \mathrm{H}), 2.85-2.76(\mathrm{~m}, 1 \mathrm{H}), 2.72(\mathrm{dt}, J=17.0$ and $5.5 \mathrm{~Hz}$, $1 \mathrm{H}), 1.45(\mathrm{~d}, J=6.6 \mathrm{~Hz}, 3 \mathrm{H}) ;{ }^{13} \mathrm{C}\left\{{ }^{1} \mathrm{H}\right\} \mathrm{NMR}\left(126 \mathrm{MHz}, \mathrm{CDCl}_{3}\right) \delta$ $178.8,148.6,148.3,142.2,128.0,127.0,126.5,125.6,123.6,111.3$, 108.7, 74.4, 56.1, 55.9, 50.3, 39.0, 25.2, 19.8. $\nu_{\max } / \mathrm{cm}^{-1}: 3410,3001$, 2836, 2580, 2533, 2410, 1577, 1512, 1360, 1257, 1218. HRMS (ESI) $m / z:[\mathrm{M}-\mathrm{Y}]^{+}$Calcd for $\mathrm{C}_{12} \mathrm{H}_{18} \mathrm{NO}_{2}{ }^{+} 208.1338$; Found 208.06 by LCMS, ESI-MS/MS. HRMS (ESI) $m / z:[M-\mathbf{X}]^{-}$Calcd for $\mathrm{C}_{8} \mathrm{H}_{7} \mathrm{O}_{3}{ }^{-}$151.0395; Found 151.03 by LCMS, ESI-MS/MS.

(R)-2-Methylpiperidinium-(S)-mandelate, (R)-11-(S)-MA.

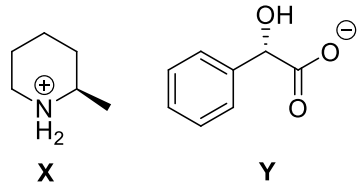

(S)-MA (2.3 g, $15.1 \mathrm{mmol})$ was added to a solution of rac-11 (1.5 g, $15.1 \mathrm{mmol})$ in tert-butyl methyl ether/methanol 24:1 $(20 \mathrm{~mL})$. The mixture was heated to reflux using a heating mantle. More of the tertbutyl methyl ether/methanol mixture was added until all solid dissolved. The mixture was cooled to room temperature and stirred overnight. The slurry was filtered to yield a white solid which was recrystallized from the same solvent mixture to give a white crystalline solid $(0.7 \mathrm{~g}, 19 \%)$ with $100 \%$ d.e. (by ${ }^{1} \mathrm{H}$ NMR in $\left.\mathrm{CDCl}_{3}, 500 \mathrm{MHz}\right)$. $\mathrm{Mp}=119-122{ }^{\circ} \mathrm{C}\left\{\right.$ lit. $\left.^{53} \mathrm{mp} 119{ }^{\circ} \mathrm{C}\right\} ;[\alpha]_{\mathrm{D}}{ }^{20}=+76.3^{\circ}$ (c 1.0, chloroform) $\left\{\right.$ lit. $^{53}[\alpha]_{\mathrm{D}}{ }^{22}=+78.0^{\circ}$ (c 1.0, chloroform) $\}$; ${ }^{1} \mathrm{H}$ NMR $\left(500 \mathrm{MHz}, \mathrm{CDCl}_{3}\right) \delta 7.46(\mathrm{~d}, J=7.3 \mathrm{~Hz}, 2 \mathrm{H}), 7.28(\mathrm{t}, J=7.3 \mathrm{~Hz}$, $2 \mathrm{H}), 7.21(\mathrm{t}, J=7.3 \mathrm{~Hz}, 1 \mathrm{H}), 4.86(\mathrm{~s}, 1 \mathrm{H}), 2.98(\mathrm{~d}, J=12.5 \mathrm{~Hz}, 1 \mathrm{H})$, $2.70-2.64(\mathrm{~m}, 1 \mathrm{H}), 2.25-2.20(\mathrm{~m}, 1 \mathrm{H}), 1.69(\mathrm{~d}, J=13.5 \mathrm{~Hz}, 1 \mathrm{H})$, $1.57-1.51(\mathrm{~m}, 3 \mathrm{H}), 1.29-1.19(\mathrm{~m}, 1 \mathrm{H}), 1.16-1.09(\mathrm{~m}, 4 \mathrm{H})$; ${ }^{13} \mathrm{C}\left\{{ }^{1} \mathrm{H}\right\}$ NMR $\left(126 \mathrm{MHz}, \mathrm{CDCl}_{3}\right) \delta 178.3,142.6,128.0,127.0$, 126.6, 74.5, 52.3, 43.8, 30.2, 22.5, 21.8, 19.1. $\nu_{\max } / \mathrm{cm}^{-1}: 3153,2696$, $2590,2544,1593,1491,1477,1444,1381,1267$. The spectral data correspond to those reported in the literature. ${ }^{53}$ HRMS (ESI) $\mathrm{m} / z$ : $[\mathrm{M}-\mathrm{Y}]^{+}$Calcd for $\mathrm{C}_{6} \mathrm{H}_{14} \mathrm{~N}^{+}$100.112624; Found 100.27 by LCMS, ESI-MS/MS; $\left\{\right.$ lit. $^{53}$ HRMS $\left.[\mathrm{M}-\mathbf{Y}]^{+}: 100.1125\right\}$; HRMS (ESI) $\mathrm{m} / z$ : $[\mathrm{M}-\mathrm{X}]^{-}$Calcd for $\mathrm{C}_{8} \mathrm{H}_{7} \mathrm{O}_{3}^{-}$151.0395; Found 151.02 by LCMS, ESI-MS/MS.

(S)-2-Methylpiperidinium-(S)-mandelate, (S)-11-(S)-MA.

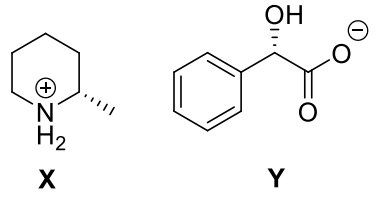

Solutions of $(S)-11(0.50 \mathrm{~g}, 5.0 \mathrm{mmol})$ in tert-butyl methyl ether $(10$ $\mathrm{mL})$ and $(S)$-MA $(0.77 \mathrm{~g}, 5.0 \mathrm{mmol})$ in the same solvent $(10 \mathrm{~mL})$ were mixed, and the slurry was heated to reflux using a heating mantle. More tert-butyl methyl ether was added $(20 \mathrm{~mL})$ followed by methanol until all solid dissolved. The reaction was cooled to room temperature with reduced stirring. After $2 \mathrm{~h}$, the mixture was filtered to give a white fluffy solid $(1.0 \mathrm{~g}, 81 \%)$ with $100 \%$ d.e. (by ${ }^{1} \mathrm{H}$ NMR in $\mathrm{CDCl}_{3}, 500 \mathrm{MHz}$ ). $\mathrm{Mp}=92-95^{\circ} \mathrm{C} ;[\alpha]_{\mathrm{D}}{ }^{20}=+63.9^{\circ}$ (c 1.0,
$\left.\mathrm{CHCl}_{3}\right) ;{ }^{1} \mathrm{H}$ NMR $\left(500 \mathrm{MHz}, \mathrm{CDCl}_{3}\right) \delta 7.46(\mathrm{~d}, J=7.6 \mathrm{~Hz}, 2 \mathrm{H})$, $7.28(\mathrm{t}, J=7.6 \mathrm{~Hz}, 2 \mathrm{H}), 7.21(\mathrm{t}, J=7.6 \mathrm{~Hz}, 1 \mathrm{H}), 4.87(\mathrm{~s}, 1 \mathrm{H}), 3.05$ $(\mathrm{d}, J=12.5 \mathrm{~Hz}, 1 \mathrm{H}), 2.50(\mathrm{td}, J=12.5$ and $3 \mathrm{~Hz}, 1 \mathrm{H}), 2.44-2.34(\mathrm{~m}$, $1 \mathrm{H}), 1.66(\mathrm{~d}, J=10.5 \mathrm{~Hz}, 1 \mathrm{H}), 1.58(\mathrm{~d}, J=14.5 \mathrm{~Hz}, 1 \mathrm{H}), 1.51(\mathrm{~d}, J=$ $14.0 \mathrm{~Hz}, 1 \mathrm{H}), 1.39-1.16(\mathrm{~m}, 3 \mathrm{H}), 1.04(\mathrm{~d}, J=6.5 \mathrm{~Hz}, 3 \mathrm{H}) ;{ }^{13} \mathrm{C}\left\{{ }^{1} \mathrm{H}\right\}$ NMR $\left(126 \mathrm{MHz}, \mathrm{CDCl}_{3}\right) \delta 178.3,142.6,128.0,127.0,126.6,74.4$, 52.1, 44.0, 30.4, 22.5, 21.7, 19.1. $\nu_{\max } / \mathrm{cm}^{-1}: 3184,2695,2582,2541$, $1627,1574,1497,1449,1382,1337,1213$. HRMS (ESI) $m / z:[M-$ $\mathrm{Y}]^{+}$Calcd for $\mathrm{C}_{6} \mathrm{H}_{14} \mathrm{~N}^{+}$100.1126; Found 100.27 by LCMS, ESI-MS/ MS. HRMS (ESI) $\mathrm{m} / z$ : $[\mathrm{M}-\mathbf{X}]^{-}$Calcd for $\mathrm{C}_{8} \mathrm{H}_{7} \mathrm{O}_{3}{ }^{-}$151.0395; Found 150.97 by LCMS, ESI-MS/MS.

Triethylammonium (S)-Mandelate.

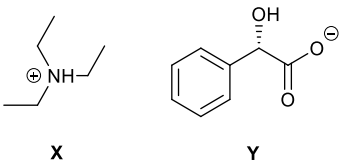

$(S)$-MA (0.3 g, $2.0 \mathrm{mmol})$ was dissolved in ethyl acetate $(5 \mathrm{~mL})$ and was added to a solution of triethylamine $(0.7 \mathrm{~mL}, 5.0 \mathrm{mmol})$ in ethyl acetate $(5 \mathrm{~mL})$. The mixture was stirred at room temperature for $3 \mathrm{~h}$. The solvent was removed in vacuo to yield the crude product as a colorless oil $(0.47 \mathrm{~g}, 94 \%)$ which was used without further purification. $[\alpha]_{\mathrm{D}}{ }^{20}=+62.1^{\circ}$ (c 1.0, methanol); ${ }^{1} \mathrm{H}$ NMR (500 MHz, $d_{6}$-DMSO) $\delta 7.39(\mathrm{~d}, J=7.3 \mathrm{~Hz}, 2 \mathrm{H}), 7.28(\mathrm{t}, J=7.3 \mathrm{~Hz}, 2 \mathrm{H})$, $7.22(\mathrm{t}, J=7.3 \mathrm{~Hz}, 1 \mathrm{H}), 4.71(\mathrm{~s}, 1 \mathrm{H}), 2.93(\mathrm{q}, J=7.3 \mathrm{~Hz}, 4 \mathrm{H}), 1.10$ $(\mathrm{t}, J=7.3 \mathrm{~Hz}, 6 \mathrm{H}) ;{ }^{13} \mathrm{C}\left\{{ }^{1} \mathrm{H}\right\}$ NMR $\left(126 \mathrm{MHz}, d_{6}\right.$-DMSO) $\delta 174.7$, $142.5,127.6,126.5,126.4,73.1,45.1,8.8 . \nu_{\max } / \mathrm{cm}^{-1}: 3324,2984$, $2431,1732,1599,1494,1478,1452,1339$. HRMS (ESI) $m / z:[M-$ $\mathrm{Y}]^{+}$Calcd for $\mathrm{C}_{6} \mathrm{H}_{16} \mathrm{~N}^{+}$102.1283; Found 102.63 by LCMS, ESI-MS/ MS. HRMS (ESI) $\mathrm{m} / z$ : $[\mathrm{M}-\mathbf{X}]^{-}$Calcd for $\mathrm{C}_{8} \mathrm{H}_{7} \mathrm{O}_{3}{ }^{-}$151.0395; Found 150.84 by LCMS, ESI-MS/MS.

Triethylammonium Phenylglyoxylate.

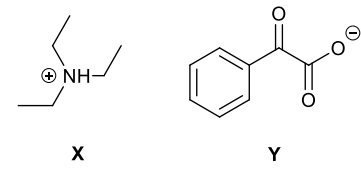

Phenylglyoxylic acid $(0.15 \mathrm{~g}, 1.0 \mathrm{mmol})$ was dissolved in ethyl acetate $(3 \mathrm{~mL})$ and was added to a solution of trimethylamine $(0.35 \mathrm{~mL}, 2.5$ $\mathrm{mmol})$ in ethyl acetate $(2 \mathrm{~mL})$. The pale yellow mixture was stirred at room temperature overnight. The solvent was removed in vacuo to yield the crude product as a thick pale yellow oil $(0.24 \mathrm{~g}, 95 \%) .{ }^{1} \mathrm{H}$ NMR (500 MHz, $d_{6}$-DMSO) $\delta 7.95-4.85(\mathrm{~m}, 2 \mathrm{H}), 7.62(\mathrm{tt}, J=7.3$ and $1.5 \mathrm{~Hz}, 1 \mathrm{H}), 7.58-7.46(\mathrm{~m}, 2 \mathrm{H}), 3.10(\mathrm{q}, J=7.4 \mathrm{~Hz}, 6 \mathrm{H}), 1.21$ $(\mathrm{t}, J=7.4 \mathrm{~Hz}, 9 \mathrm{H}) ;{ }^{13} \mathrm{C}\left\{{ }^{1} \mathrm{H}\right\}$ NMR $\left(126 \mathrm{MHz}, d_{6}\right.$-DMSO) $\delta 195.1$, 169.6, 134.1, 133.0, 128.9, 128.5, 45.4, 8.5. $\nu_{\max } / \mathrm{cm}^{-1}: 2987,2639$, $2489,1676,1594,1475,1450,1398,1311,1224$. HRMS (ESI) $\mathrm{m} / z$ : $[\mathrm{M}-\mathrm{Y}]^{+}$Calcd for $\mathrm{C}_{6} \mathrm{H}_{16} \mathrm{~N}^{+}$102.1283; Found 102.35 by LCMS, ESI-MS/MS. HRMS (ESI) $m / z$ : $[\mathbf{M}-\mathbf{X}]^{-}$Calcd for $\mathrm{C}_{8} \mathrm{H}_{5} \mathrm{O}_{3}{ }^{-}$ 149.0239; Found 148.92 by LCMS, ESI-MS/MS.

Resolution-Racemization-Recycle Process. The experimental setup is shown in Supporting Information Figures S8.1 and S8.2. The $50 \mathrm{~mL}$ magnetically stirred crystallizer, used at ambient temperature, was fitted with an in-line sintered glass filter, suitable to retain the crystals and allow the separation from the mother liquors. A PTFE lid with inlet and outlet tubes was tightly fitted to prevent solvent evaporation. The mother liquors were pumped through the heated racemization column using a Jasco pump and recirculated back to the crystallizer. The parameters used for each of the $\mathrm{R}^{3}$ processes are shown in Supporting Information Tables S8.1S8.12. The diastereomeric salts were made by dissolving the racemic amine and resolving acid in the chosen solvent at a supersaturating concentration to cause precipitation. Otherwise, reactions were seeded with the pure diastereomeric salt $(5 \% \mathrm{w} / \mathrm{w})$. An initial sample was taken $(150 \mu \mathrm{L})$ and prepared for analysis by filtering the mother liquor and diluting in ethyl acetate $(2850 \mu \mathrm{L})$ and basified by aqueous $\mathrm{Na}_{2} \mathrm{CO}_{3}(10 \% \mathrm{w} / \mathrm{w}, 3 \mathrm{~mL})$; the organic layer was dried with $\mathrm{MgSO}_{4}$ and filtered through a plug of Celite. The crystals collected from each 
sample were dissolved in dichloromethane, dried in vacuo, and analyzed by ${ }^{1} \mathrm{H} \mathrm{NMR}\left(\mathrm{CDCl}_{3}, 500 \mathrm{MHz}\right)$. The pump was started, and samples were taken as described after each complete recirculation of the system volume, for the designated number of cycles. The activity of the catalyst was determined at the end of the reaction by pumping the optically active amine through the heated fixed bed for 3-4 reactor volumes (i.e., steady state) (Supporting Information section 9).

\section{ASSOCIATED CONTENT}

\section{(s) Supporting Information}

The Supporting Information is available free of charge at https://pubs.acs.org/doi/10.1021/acs.joc.0c02617.

Analytical data; synthesis and characterization of other compounds; solubility measurements; details of racemizations; diastereomeric resolutions; and catalyst activity assay (PDF)

\section{Accession Codes}

CCDC 2041125, 2041131, and 2041218 contain the supplementary crystallographic data for this paper. These data can be obtained free of charge via www.ccdc.cam.ac.uk/ data_request/cif, or by emailing data_request@ccdc.cam.ac. uk, or by contacting The Cambridge Crystallographic Data Centre, 12 Union Road, Cambridge CB2 1EZ, UK; fax: +44 1223336033.

\section{AUTHOR INFORMATION}

\section{Corresponding Author}

A. John Blacker - School of Chemistry and School of Chemical and Process Engineering. Institute of Process Research and Development, University of Leeds, Leeds LS2 9JT, U.K.; (1) orcid.org/0000-0003-4898-2712; Email: j.blacker@leeds.ac.uk

\section{Authors}

Maria H. T. Kwan - School of Chemistry and School of Chemical and Process Engineering. Institute of Process Research and Development, University of Leeds, Leeds LS2 9JT, U.K.

Jessica Breen - School of Chemistry and School of Chemical and Process Engineering. Institute of Process Research and Development, University of Leeds, Leeds LS2 9JT, U.K.

Martin Bowden - Syngenta, Bracknell RG42 6EY, U.K.

Louis Conway - Syngenta, Bracknell RG42 6EY, U.K.

Ben Crossley - ApexMolecular, Alderley Park SK10 4TG, U.K.

Martin F. Jones - Pharmaceutical Technology and Development, AstraZeneca, Macclesfield SK10 2NA, U.K.

Rachel Munday - Pharmaceutical Technology and Development, AstraZeneca, Macclesfield SK10 2NA, U.K.

Nisha P. B. Pokar - School of Chemistry and School of Chemical and Process Engineering. Institute of Process Research and Development, University of Leeds, Leeds LS2 9JT, U.K.

Thomas Screen - ApexMolecular, Alderley Park SK10 4TG, U.K.

Complete contact information is available at:

https://pubs.acs.org/10.1021/acs.joc.0c02617

\section{Notes}

The authors declare no competing financial interest.

\section{ACKNOWLEDGMENTS}

We gratefully acknowledge AstraZeneca and EPSRC for the financial support of M.H.T.K. and N.P.B.P. through CASE awards EP/L50550X/1 and NP EP/R51200X1, respectively. J.B. thanks Innovate UK, EPSRC, AstraZeneca, Syngenta, Pfizer, Dr Reddys, and ApexMolecular for support and collaboration under grant EP/K504154/1.

\section{DEDICATION}

This paper is dedicated to the memory of Prof. Takao Ikariya.

\section{REFERENCES}

(1) Ebbers, E. J.; Ariaans, G. J. A.; Houbiers, J. P. M.; Bruggink, A.; Zwanenburg, B. Controlled racemization of optically active organic compounds: Prospects for asymmetric transformation. Tetrahedron 1997, 53 (28), 9417-9476.

(2) Nugent, T. C. Chiral amine synthesis: methods, developments and applications; Wiley-VCH: Weinheim, Germany, 2010.

(3) Li, W.; Zhang, X. Stereoselective formation of amines. SpringerVerlag: Berlin, Heidelberg, 2014.

(4) Guo, F.; Berglund, P. Transaminase biocatalysis: optimization and application. Green Chem. 2017, 19 (2), 333-360.

(5) Heller, D.; De Vries, A. H. M.; De Vries, J. G. Catalyst Inhibition and Deactivation in Homogeneous Hydrogenation. The Handbook of Homogeneous Hydrogenation; De Vries, J. G., Elsevier, C. J., Eds.; WILEY-VCH Verlag GmbH \& Co KGaA, 2007.

(6) Sheldon, R. A.; Brady, D. The limits to biocatalysis: pushing the envelope. Chem. Commun. 2018, 54 (48), 6088-6104.

(7) Wang, Y.; Chen, A. Crystallization-Based Separation of Enantiomers. Stereoselective Synthesis of Drugs and Natural Products 2013, 1-20.

(8) Parvulescu, A.; Janssens, J.; Vanderleyden, J.; Vos, D. Heterogeneous Catalysts for Racemization and Dynamic Kinetic Resolution of Amines and Secondary Alcohols. Top. Catal. 2010, 53 (13-14), 931-941.

(9) Verho, O.; Backvall, J.-E. Chemoenzymatic dynamic kinetic resolution: a powerful tool for the preparation of enantiomerically pure alcohols and amines. J. Am. Chem. Soc. 2015, 137 (12), 39964009.

(10) Havinga, E. Spontaneous formation of optically active substances. Biochim. Biophys. Acta 1954, 13, 171-174.

(11) Viedma, C. Chiral Symmetry Breaking During Crystallization: Complete Chiral Purity Induced by Nonlinear Autocatalysis and Recycling. Phys. Rev. Lett. 2005, 94 (6), No. 065504.

(12) Black, S. N.; Williams, L. J.; Davey, R. J.; Moffatt, F.; Jones, R. V. H.; McEwan, D. M.; Sadler, D. E. The preparation of enantiomers of paclobutrazol: A crystal chemistry approach. Tetrahedron 1989, 45 (9), 2677-2682.

(13) Noorduin, W. L.; Izumi, T.; Millemaggi, A.; Leeman, M.; Meekes, H.; Van Enckevort, W. J. P.; Kellogg, R. M.; Kaptein, B.; Vlieg, E.; Blackmond, D. G. Emergence of a Single Solid Chiral State from a Nearly Racemic Amino Acid Derivative. J. Am. Chem. Soc. 2008, 130 (4), 1158-1159.

(14) Brands, K. M. J.; Davies, A. J. Crystallization-Induced Diastereomer Transformations. Chem. Rev. 2006, 106 (7), 27112733.

(15) Palmans, A. R. A. Deracemisations under kinetic and thermodynamic control. Molecular Systems Design \& Engineering 2017, 2 (1), 34-46.

(16) Blacker, A. J.; Stirling, M. J.; Page, M. I. Catalytic racemisation of chiral amines and application in dynamic kinetic resolution. Org. Process Res. Dev. 2007, 11 (3), 642-648.

(17) Anderson, N. G. Developing Processes for CrystallizationInduced Asymmetric Transformation. Org. Process Res. Dev. 2005, 9 (6), 800-813.

(18) Hein, J. E.; Huynh Cao, B.; Viedma, C.; Kellogg, R. M.; Blackmond, D. G. Pasteur's Tweezers Revisited: On the Mechanism 
of Attrition-Enhanced Deracemization and Resolution of Chiral Conglomerate Solids. J. Am. Chem. Soc. 2012, 134 (30), 1262912636.

(19) Jacques, J.; Collet, A.; Wilen, S. H. Enantiomers, racemates, and resolutions; Wiley: 1981.

(20) Brock, C. P.; Schweizer, W. B.; Dunitz, J. D. On the validity of Wallach's rule: on the density and stability of racemic crystals compared with their chiral counterparts. J. Am. Chem. Soc. 1991, 113 (26), 9811-9820.

(21) Otero-de-la-Roza, A.; Hein, J. E.; Johnson, E. R. Reevaluating the Stability and Prevalence of Conglomerates: Implications for Preferential Crystallization. Cryst. Growth Des. 2016, 16 (10), 60556059.

(22) Lee, W. K.; Park, Y. S.; Beak, P. Dynamic Thermodynamic Resolution: Advantage by Separation of Equilibration and Resolution. Acc. Chem. Res. 2009, 42 (2), 224-234.

(23) Reetz, M. T.; Schimossek, K. Lipase-Catalyzed Dynamic Kinetic Resolution of Chiral Amines: Use of Palladium as the Racemization Catalyst. Chimia 1996, 50 (12), 668-669.

(24) Parvulescu, A. N.; Jacobs, P. A.; De Vos, D. E. Palladium Catalysts on Alkaline-Earth Supports for Racemization and Dynamic Kinetic Resolution of Benzylic Amines. Chem. - Eur. J. 2007, 13 (7), 2034-2043.

(25) Jiang, C.-j.; Cheng, G.-I. Racemization of Amines and Related Derivatives Leading to Their Dynamic Kinetic Resolution. Curr. Org. Chem. 2013, 17 (11), 1225-1234.

(26) Samec, J. S. M.; Bäckvall, J.-E. Ruthenium-Catalyzed Transfer Hydrogenation of Imines by Propan-2-ol in Benzene. Chem. - Eur. J. 2002, 8 (13), 2955-2961.

(27) Stirling, M. J.; Mwansa, J. M.; Sweeney, G.; Blacker, A. J.; Page, M. I. The kinetics and mechanism of the organo-iridium catalysed racemisation of amines. Org. Biomol. Chem. 2016, 14 (29), 70927098.

(28) Stirling, M.; Blacker, A. J.; Page, M. I. Chemoenzymatic dynamic kinetic resolution of secondary amines. Tetrahedron Lett. 2007, 48, 1247-1250.

(29) Pamies, O.; Ell, A. H.; Samec, J. S. M.; Hermanns, N.; Backvall, J.-E. An efficient and mild ruthenium-catalyzed racemization of amines: application to the synthesis of enantiomerically pure amines. Tetrahedron Lett. 2002, 43 (26), 4699-4702.

(30) Thalen, L. K.; Backvall, J.-E. Development of dynamic kinetic resolution on large scale for $( \pm)-1$-phenylethylamine. Beilstein J. Org. Chem. 2010, 6, 823-9.

(31) He, D.; Horváth, I. T. Application of silica-supported Shvo's catalysts for transfer hydrogenation of levulinic acid with formic acid. J. Organomet. Chem. 2017, 847, 263-269.

(32) Lucas, S. J.; Crossley, B. D.; Pettman, A. J.; Vassileiou, A. D.; Screen, T. E. O.; Blacker, A. J.; McGowan, P. C. A robust method to heterogenise and recycle group 9 catalysts. Chem. Commun. 2013, 49 (49), 5562-5564.

(33) Kawakami, Y.; Borissova, A.; Chapman, M. R.; Goltz, G.; Koltsova, E.; Mitrichev, I.; Blacker, A. J. Continuous Flow Asymmetric Transfer Hydrogenation with Long Catalyst Lifetime and Low Metal Leaching. Eur. J. Org. Chem. 2019, 2019 (45), 74997505.

(34) Falus, P.; Cerioli, L.; Bajnóczi, G.; Boros, Z.; Weiser, D.; Nagy, J.; Tessaro, D.; Servi, S.; Poppe, L. A Continuous-Flow Cascade Reactor System for Subtilisin A- Catalyzed Dynamic Kinetic Resolution of N-tert-Butyloxycarbonylphenylalanine Ethyl Thioester with Benzylamine. Adv. Synth. Catal. 2016, 358 (10), 1608-1617.

(35) de Miranda, A. S.; de M. Silva, M. V.; Dias, F. C.; de Souza, S. P.; Leao, R. A. C.; de Souza, R. O. M. A. Continuous flow dynamic kinetic resolution of rac-1-phenylethanol using a single packed-bed containing immobilized CAL-B lipase and VOSO4 as racemization catalysts. Reaction Chemistry \& Engineering 2017, 2 (3), 375-381.

(36) Farkas, E.; Oláh, M.; Földi, A.; Kóti, J.; Éles, J.; Nagy, J.; Gal, C. A.; Paizs, C.; Hornyánszky, G.; Poppe, L. Chemoenzymatic Dynamic Kinetic Resolution of Amines in Fully Continuous-Flow Mode. Org. Lett. 2018, 20 (24), 8052-8056.
(37) Pámies, O.; Éll, A. H.; Samec, J. S. M.; Hermanns, N.; Bäckvall, J.-E. An efficient and mild ruthenium-catalyzed racemization of amines: application to the synthesis of enantiomerically pure amines. Tetrahedron Lett. 2002, 43, 4699-4702.

(38) Kwan, M. H. T.; Pokar, N. P. B.; Good, C.; Jones, M. F.; Munday, R.; Screen, T.; Blacker, A. J. Deactivation Mechanisms of Iodo-Iridium Catalysts in Chiral Amine Racemization. Tetrahedron 2020, 131823.

(39) Wu, X.; Li, X.; King, F.; Xiao, J. Insight into and Practical Application of $\mathrm{pH}$-Controlled Asymmetric Transfer Hydrogenation of Aromatic Ketones in Water. Angew. Chem., Int. Ed. 2005, 44 (22), 3407-3411.

(40) Resolution by Formation and Fractional Crystallization of Diastereomeric Salts. CRC Handbook of Optical Resolutions via Diastereomeric Salt Formation; Kozma, D., Ed.; CRC Press: 2001.

(41) Gomm, A.; Lewis, W.; Green, A. P.; O’Reilly, E. A New Generation of Smart Amine Donors for Transaminase-Mediated Biotransformations. Chem. - Eur. J. 2016, 22 (36), 12692-12695.

(42) Ferreira, F. C.; Ghazali, N. F.; Cocchini, U.; Livingston, A. G. Rational approach to the selection of conditions for diastereomeric resolution of chiral amines by diacid resolving agents. Tetrahedron: Asymmetry 2006, 17 (9), 1337-1348.

(43) Wakchaure, V. N.; Kaib, P. S. J.; Leutzsch, M.; List, B. Disulfonimide-catalysed asymmetric reduction of $\mathrm{N}$-alkyl imines. Angew. Chem., Int. Ed. 2015, 54, 11852-11856.

(44) Ezawa, M.; Moriyama, K.; Togo, H. Transformation of N,Ndiisopropylarylmethylamines into $\mathrm{N}$-isopropylarylmethylamines with molecular iodine. Tetrahedron Lett. 2015, 56, 6689-6692.

(45) Johannes, M.; Altmann, K.-H. A Ring-Closing MetathesisBased Approach to the Synthesis of (+)-Tetrabenazine. Org. Lett. 2012, 14, 3752-3755.

(46) Zhu, R.; Xu, Z.; Ding, W.; Liu, S.; Shi, X.; Lu, X. Efficient and Practical Syntheses of Enantiomerically Pure (S)-(-)-Norcryptostyline I, (S)-(-)-Norcryptostyline II, (R)-(+)-Salsolidine and (S)(-)-Norlaudanosine via a Resolution-Racemization Method. Chin. J. Chem. 2014, 32, 1039-1048.

(47) Brossi, A.; Dolan, L. A.; Teitel, S. Organic Syntheses Collective, Vol. 6; Wiley: 1988.

(48) Zhu, R.; Xu, Z.; Ding, W.; Liu, S.; Shi, X.; Lu, X. Wei Ding, Shiling Liu, Xiaoxin Shi, Xia Lu, Efficient and practical syntheses of enantiomerically pure $(S)-(-)$-Norcryptostyline I, $(S)$-(-)-Norcryptostyline II, $(R)-(+)$-Salsolidine and $(S)-(-)$-Norlaudansosine via a resolution-racemisation method. Chin. J. Chem. 2014, 32, 1039-1048.

(49) Prech, J.; Vaclavik, J.; Pechacek, J.; Vilhanova, B.; Januscak, J.; Syslova, K.; Pazout, R.; Maixner, J.; Zapal, J.; Kuzma, M.; Kacer, P. Asymmetric transfer hydrogenation of 1-phenyl dihydroisoquinolines using $\mathrm{Ru}(\mathrm{II})$ diamine catalysts. Catal. Commun. 2013, 36, 67-70.

(50) Li, Z.-W.; Wang, T.-L.; He, Y.-M.; Wang, Z.-J.; Fan, Q.-H.; Pan, J.; Xu, L.-J. Air-Stable and Phosphine-Free Iridium Catalysts for Highly Enantioselective Hydrogenation of Quinoline Derivatives. Org. Lett. 2008, 10 (22), 5265-5268.

(51) Al-Sehemi, A. G.; Atkinson, R. S.; Fawcett, J. Kinetic resolution of amines with enantiopure 3-N,Ndiacylaminoquinazolin-4(3H)-ones. J. Chem. Soc., Perkin Trans. 1 2002, 257-274.

(52) Metkar, P. S.; Scialdone, M. A.; Moloy, K. G. Lysinol: a renewably resourced alternative to petrochemical polyamines and aminoalcohols. Green Chem. 2014, 16, 4575-4586.

(53) Vu, V. H.; Jouanno, L.-A.; Cheignon, A.; Roisnel, T.; Dorcet, V.; Sinbandhit, S.; Hurvois, J.-P. Modified Fry Cyanation of a Chiral Pyridinium Salt: Asymmetric Syntheses of $(-)$-Coniine and (-)-Solenopsin. A Eur. J. Org. Chem. 2013, 2013, 5464-5474. 